This is a self-archiving document (manuscript version):

Young people's travel behavior - Using the life-oriented approach to understand the acceptance of autonomous driving

By: Herrenkind, Bernd; Nastjuk, Ilja; Brendel, Alfred Benedikt; Trang, Simon; Kolbe, Lutz M.

Published in: Transportation Research Part D: Transport and Environment

Volume 74, September 2019, Pages 214-233 (Please be aware: Page numbering in this manuscript can be different to published version!) Publisher: Elsevier | Year: 2019

DOI: 10.1016/j.trd.2019.07.023

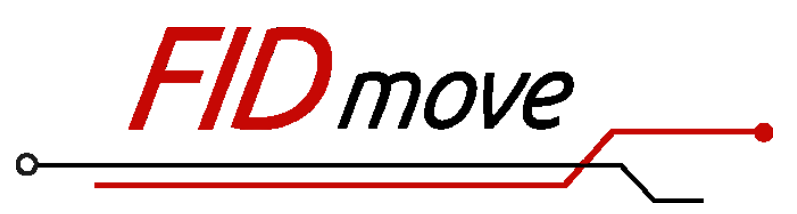
Brought to you by the Scientific Information Service for Mobility and Transport Research

Fachinformationsdienst Mobilitäts- und Verkehrsforschung

Website: www.fid-move.de

Repository: publish.fid-move.de

Contact: publish@fid-move.de

(C) 2021. This manuscript version is made available under the CC-BYNC-ND 4.0 license. 
Herrenkind, Bernd; Nastjuk, Ilja; Brendel, Alfred Benedikt;

Trang, Simon; Kolbe, Lutz M.

\title{
YOUNG PEOPLE'S TRAVEL BEHAVIOR - USING THE LIFE-ORIENTED APPROACH TO UNDERSTAND THE ACCEPTANCE OF AUTONOMOUS DRIVING
}

\author{
Research Paper
}

\begin{abstract}
The self-driving public bus (SDPB) holds the potential to replace human-operated driving with more eco-friendly means and is therefore a valuable mobility solution for our future. The SDPB is based on the innovative technology of autonomous driving, which can only be guaranteed future market success with broad enough user acceptance. This acceptance is thus an essential factor for the growth of SDPB services. In this context, the travel behavior of young people is particularly interesting, as its development will continually demonstrate future mobility behavior trends. However, little research has been conducted regarding the best methods for motivating young people to accept SDPBs as a viable mode of travel.

To address this topic, we first conducted a literature review, identifying factors that potentially influence SDPB acceptance. Subsequently, we developed a comprehensive research model based on the life-oriented approach and the technology acceptance model. This conceptualization was validated by a survey of 268 SDPB riders in real-world traffic. The results reveal several novel factors influencing the acceptance of SDPBs, in particular regarding differences in age. Our research contributes to existing research on both the life-oriented and travel behavior approaches by highlighting age differences and their importance in the field. For instance, our findings demonstrate a vital need to account for age differences when deriving policy implications for future mobility solutions.
\end{abstract}

Keywords

Young Travel Behavior, Autonomous Driving, Life-Oriented Approach, Acceptance Research 


\section{$1 \quad$ Introduction}

\subsection{Background}

Increased atmospheric concentrations of greenhouse gases, caused largely by the widespread production and operation of cars, remains a stark example of observable climate change (UN-DESA, 2014). The total number of vehicle trips made in China, the USA, and Germany is expected to increase by 3 9\% by the year 2035 (Trommer et al., 2016). In addition, 66\% of the world's population will be living in inner-city areas by 2050 (UN-DESA, 2014). As the concentration of residents increases, private and vehicle-based mobility will gradually become less feasible. In fact, traditional car-bound transport infrastructure would most likely generate increased traffic congestion and road risks, in addition to higher levels of noise and emissions (Nijland et al., 2015; Nykvist and Whitmarsh, 2008; Pavone et al., 2012).

Against this background, autonomous driving (AD) has been proposed as a valuable approach for advancing the development and implementation of sustainable and smart mobility solutions. These solutions must meet the challenges of not only current and future developments in the transportation sector, but also other potential future travel needs (Bernhart et al., 2018; Brendel et al., 2017; Pakusch et al., 2018b; Schmidt et al., 2018). AD offers several advantages on a societal level, offering significant support in the realm of sustainability. In addition, AD vehicles increase safety by virtually eliminating the possibility of human error, often caused by factors such as age, disability, stress, tiredness, drug abuse, or inexperience (Beiker, 2012; Shanker et al., 2013). Supporters of AD have estimated that operating driverless cars could reduce the number of road-associated deaths by up to $90 \%$ by the middle of this century (Bertoncello and Wee, 2015). Furthermore, research has highlighted AD's environmental potential, based on its reduced carbon dioxide emissions and fuel consumption through the gradual optimization of traffic flow and the efficient use of braking and acceleration processes (Brown et al., 2014; Milakis et al., 2017).

To capitalize on the advantages AD offers, it could be beneficial to first introduce AD as a publicly shared mobility solution, e.g., a public bus system. Commercially, AD vehicles are best exploited by a model that collects passengers at any point and drives them to their respective destinations (International Transport Forum, 2015; Münzel et al., 2018), making this transportation service a direct competitor of companies such as Uber and Lyft. A public self-driving bus (SDPB) combines public transport with an environmentally friendly driving system, thanks to its more efficient driving method. Through a more eco-friendly driving style, $\mathrm{AD}$ vehicles can help regulate excessive energy consumption, merge existing transportation options into a single integrative mode of transportation (e.g., by replacing both ride- and car-sharing with an autonomous, on-demand shared service), minimize traffic congestion, reduce travel costs per kilometer, and moderate air pollution (Hars, 2015; Herminghaus, 2019).

To ensure the widespread diffusion of SDPBs, their acceptance by the initial target group must first be established. Ignoring this step would likely result in detracting debates, as is currently the case for the topic of trams (Lo, 2012). For years, young people were represented as one of the most-if not the most - car-oriented age groups in Germany, "serving as a bellwether for a trend towards more caroriented lifestyles of all groups of society" (Kuhnimhof et al., 2012, p. 443). Previous investigations established that earning a driver's license and car ownership can be distinguished as expected changes for this age group. However, more recent observations have noted declining interest in car ownership and usage among young people in Germany as well as some other developed countries (Litman, 2006; Millard-Ball and Schipper, 2011; Newman and Kenworthy, 2011; Zumkeller et al., 2004). Similarly, studies have indicated a decline in the share of young adults possessing a driver's license (Delbosc, 2017; Delbosc and Currie, 2014; Le Vine et al., 2014). Nevertheless, it is safe to say that the young generation of today will shape the mobility patterns of tomorrow. This then raises the question of how to steer young people toward using SDPBs, thus reducing the use of privately-owned cars and helping to create a more environmentally sustainable future. 
An increasing proportion of young drivers in Europe - especially in Germany - are making use of alternative means of transport, demonstrating an increase in multimodal driving behavior. This could be due to various factors, such as general changes in how mobility is viewed, improvement in and promotion of alternate transportation (Kuhnimhof et al., 2012), the greater increase in costs of traveling by car as compared to public transport, or a combination of them. Several studies have indicated that the 2008 financial crisis in Europe could have also fostered a change in mobility behavior (e.g., Nielsen, 2015; Papagiannakis et al., 2018; Ulfarsson et al., 2015). The gender gaps among young German car drivers have mostly narrowed, primarily because young men have shifted their mobility patterns away from car ownership and drive less than before (Kuhnimhof et al., 2012). These developments reveal the change in the travel behavior of young people, pushing toward the demand for new mobility services. The challenge in meeting this demand is to ensure that these new services are environmentally sustainable (like SDPBs), avoiding a rise in single-person ride-hailing services, which congest our cities and pollute our air.

\section{$1.2 \quad$ Research Objectives}

The determinants differentiating young people's travel behavior from that of other age groups are not completely clear. However, a better understanding of these determinants is of great importance for a more sustainable view of travel behavior (e.g., Alemi et al., 2018; Best and Lanzendorf, 2005; Buehler and Nobis, 2010; Kuhnimhof et al., 2012). Moreover, researchers must find answers enabling policymakers to take appropriate measures toward reaching a sustainable mobility future. In this context, end-users' acceptance of AD is crucial for enabling it to become part of the future traffic (Eugensson et al., 2013) and rendering SDPBs a realistic mobility solution. In light of this necessity, urban and transportation researchers have faced criticism claiming that they "[...] seem to have been more fascinated and driven by the application of a particular model, rather than the desire to develop new or adjusted models that sufficiently rectify the specific characteristics of the decision's problem at hand" (Rasouli and Timmermans, 2017, p.454).

One way of addressing this shortcoming is by applying a life-oriented approach (Dykstra and van Wissen, 1999; Lanzendorf, 2003; Mayer and Tuma, 1990) to develop such adjusted models. The lifeoriented approach proposes a paradigm shift, attempting to incorporate various life-related factors into life choices for improving overall quality of life. For example, within the life-oriented approach, age is a symbol of life experience, which in turn has different implications and meanings for subsequent life choices and daily activities. Life domains, such as place of residence, income, and education, are also relevant within the approach (Zhang and Van Acker, 2017). This approach is suitable, as many variables concerning our life choices (e.g., family life, social life, health, job) are related to decisions on travel behavior-itself a life domain. Often, the events taking place become the focal points for important life decisions that entail relatively long-term implications, including demographic events, job changes, or the purchase of important resources (e.g., a home or vehicle.) These life events can be interdependent, possibly leading to dynamic changes in travel behavior. In contrast, the decision-making issues are mapped primarily in urban and transport sciences using classical discrete selection models (Zhang and Van Acker, 2017). However, because these decisions differ significantly from daily decisions, alternative modeling approaches could easily be more advantageous (Rasouli and Timmermans, 2017; Zhang and Van Acker, 2017).

Accordingly, the aim of this paper is to provide insight into young people's acceptance of SDPBs in comparison to that of older people, as young people hold the potential to make future travel behavior more sustainable. Addressing criticism regarding the narrow scope of transportation research (e.g., Rasouli and Timmermans, 2017; Zhang and Van Acker, 2017), this paper examines the extent to which the acceptance of SDPBs in the model of young people differs from that of older people in the context of their life choices.

To address the research objective, we first derived a comprehensive research model based on the technology acceptance model (TAM) proposed by (Davis et al., 1989) and enriched with aspects of Zhang's life-oriented approach (Zhang, 2017a). We designed a survey to test the hypothesized rela- 
tionships within the resulting research model. The survey was conducted in Germany, where the country's first SDPB was launched in real-world traffic for a defined trial period. Only those who had already ridden a SDPB were allowed to take part in the survey. Our sample was divided into two age groups. In line with Melia et al. (2018) and Moos (2016), we defined the group of young people as those up to the age of 35. To reduce complexity, we consider middle-aged adults (35-60) and those older than 60 together in one group as older people (Freund and Ritter, 2009; Li et al., 2012). We subdivided the sample as such for three reasons: First, to achieve widespread SDPB acceptance, it is important to develop an understanding for each age group, especially when there is a clear trend toward an aging society (Arshad and Bhat, 2013). Furthermore, studies have demonstrated that the increased willingness of older people to travel and be mobile is exasperating congestion and pollution, emphasizing the need to understand the acceptance of sustainable mobility solutions on an age-group level (e.g., Oxley and Whelan, 2008). Second, findings from other age groups are important in order to reasonably demarcate the category of young people (Hiscock, 2000). Third, as with all other age groups, young people are continually getting older. However, as there remains the possibility that they will adopt the mobility behavior of people in old age rather than carrying their current travel behavior through life, demonstrating an understanding of older people is likewise important (Kuhnimhof et al., 2012). Thus, the inclusion of the elderly group not only makes comparison with the young group possible but also allows changing aspects to be included in the derivation and reevaluation of policies. Based on the findings, the study concludes with a discussion of the results and several implications for policymakers, outlining a better understanding of young people's travel behavior.

\section{Theoretical Framework}

\subsection{Technology Acceptance Model}

TAM was developed by Davis and published in 1989, with the model's aim being to explain the determinants for the use or non-use of a new technology, innovation, or information system (Davis, 1989). It represents one of the most influential models for investigating the acceptance of technological innovations (e.g., King and He, 2006; Schepers and Wetzels, 2007; Wu et al., 2011).

As a pivotal model, TAM explains what induces individuals to accept and use a technology, based on the assumption that an individual's actual behavior persists by his or her intention to use it. At the center of TAM is the assumption of an intention to use a technology or information system determined by two constructs: perceived usefulness and perceived ease of use. Davis' (1989) TAM (illustrated in Figure 1) defines perceived usefulness as the degree of improvement in the work performance that a person believes is achieved with a particular system, while perceived ease of use refers to how uncomplicated an individual believes the use of a specific system to be.

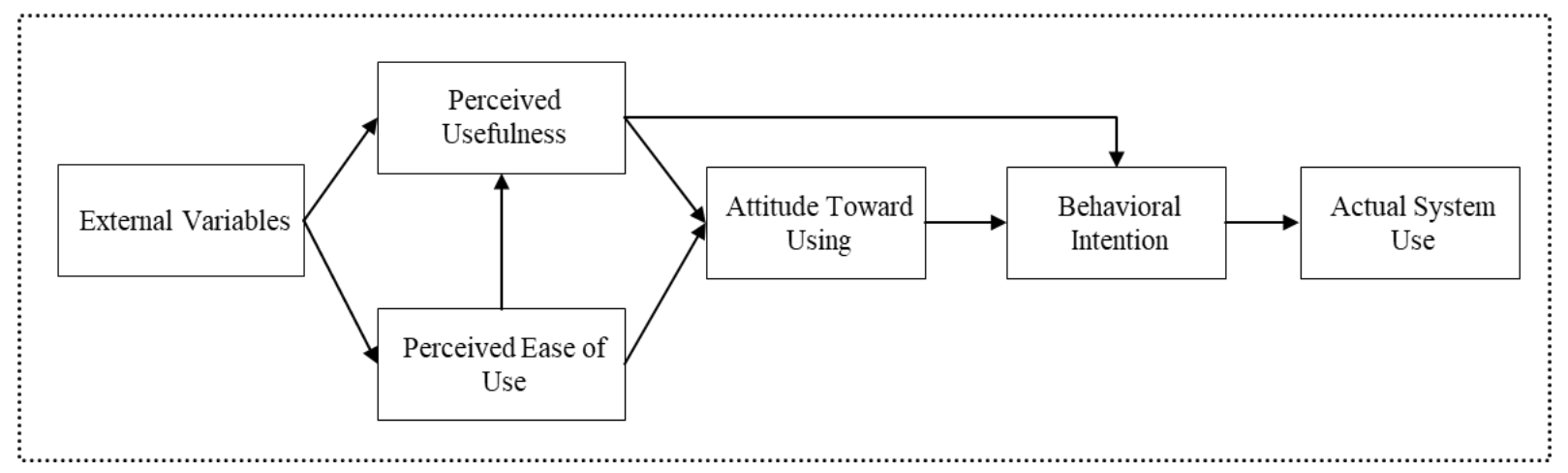

Figure 1. Technology Acceptance Model (based on Davis 1989)

Högg (2010) acknowledged the importance of the behavioral intention variable for predicting actual use, especially in connection with research for recent and even hypothetical or future-based technologies not yet on the market. In this regard, Davis and Venkatesh (2004) assessed TAM's ability to pre- 
dict acceptance for technologies with which users have only limited or no hands-on experience. The authors found TAM to be a useful model in predicting the acceptance of technologies for their antecedent stages of design and development.

TAM and its extended versions have been shown to be suitable for examining the acceptance of future technologies (e.g., Koivumäki et al., 2017; Martignoni et al., 2008), including the specific context of AD (e.g., Choi and Ji, 2015). Although studies have demonstrated that extensions of TAM (i.e., TAM2 and the unified theory of acceptance and use of technology [UTAUT]) are also useful for examining the adoption of new transportation technologies, such extension have also been criticized for being based on empirical and not theoretical considerations (Kim et al., 2009; Pedersen and Nysveen, 2003). As a method for predicting technological acceptance in a variety of areas, TAM remains the most robust and powerful option, especially in comparison to other alternative models (Lee et al., 2003). These alternatives contain a plethora of theories, such as the theory of reasoned action and the theory of planned behavior. In comparison, TAM itself has been shown to be able explain approximately $40 \%$ of the variance between behavior-related intentions and an individual's actual behavior (King and He, 2006; Venkatesh, 2000). Moreover, Davis and Venkatesh (2004) determined that the "expectations about a system captured using reliable and valid measures of key expectations, even before hands-on use of the system, are predictive of those that would have been obtained after brief use of a test prototype, as well as after several weeks of actual system use" (p. 44). With this in mind, we argue that TAM, along with its basic constructs, is an appropriate model for investigating SDPB acceptance. This particular context needs an adapted model where TAM is building a solid basis. As other models, such as UTAUT I and II, are already extended, additional construct extensions could lead to interferences.

\subsection{Life-Oriented Approach}

The life-oriented approach was developed in the 1990s to explain life decisions and their interrelationships. Demographic and housing researchers in several fields carried out the initial investigations related to this approach (Dykstra and van Wissen, 1999; Lanzendorf, 2003; Mayer and Tuma, 1990). The approach is conceptually based on how the decisions affecting individual lives are interdependent and closely related (Lanzendorf, 2003). This includes decisions in the areas of residence, neighborhood, health, work, and family life. As a result, a life decision in one sector can arise from a decision within another sector while at the same time influencing further decisions (Zhang and Xiong, 2015). Two interrelated concepts are in play here: quality of life (QOL) and life choices.

Researchers from the fields of geography, urban planning, and travel behavior have recently shown increased interest in life-oriented factors that influence the dynamics of travel-related decisions (e.g., Beige and Axhausen, 2012, 2008; Chatterjee and Scheiner, 2015; Clark et al., 2016; Delbosc and Nakanishi, 2017; Fatmi and Habib, 2016; Müggenburg et al., 2015; Oakil et al., 2011b, 2011a, Scheiner, 2014, 2018; Scheiner and Holz-Rau, 2013; Schoenduwe et al., 2015; Verhoeven et al., 2007, 2005b, 2005a; Wang et al., 2018). For instance, Clark et al. (2016) proved that changes in the individual commuting mode are mainly caused by changes in the workplace distance, which occur in response to a change of job or a change in residence. Moreover, the study shows that in addition to spatial concerns, life events and individual environmental attitudes also cause changes. Additionally, Oakil et al. (2014) and Verhoeven et al. (2006) investigated the effects of life-changing events (e.g., employment or residency changes) on traffic behavior and the choice of transport mode. In light of this, Lanzendorf (2003) and van der Waerden et al. (2003) can be seen as pioneers in the field of lifeoriented travel behavior and transportation research; both contributions examine how moving to a new place of residence or other important changes in peoples' private lives affect travel behavior and motorization. Apart from this, Beige and Axhausen (2012) demonstrated that over the course of one's life there are strong connections between the various turning points (e.g., personal and familial events) and long-term mobility decisions, as events generally take place simultaneously. Scheiner and Holz-Rau (2013) demonstrate that changes in the travel mode specific trip rates, with regard to the mobility biography, are mainly caused by induced life changes, personal and household sociodemographic, and 
regional relationships. Finally, Müggenburg et al. (2015) summarizes the existing literature in the field of mobility biographies by deriving a theoretical framework which shows the relationship between long-term processes, life events, interventions and long-term and daily mobility decisions.

The life-oriented approach is also intended to support policy decisions, which have an impact evident in various areas of public life (Zhang, 2017a). (Zhang, 2017b) asserts that ignorance of the connections among the various decisions and the inability to see through their interactions both lead to a false reception of any factual evidence. Hence, decisions are measured more vehemently, only within the limits of one's own discipline. Against this background, decision-makers require a more complete recognition of human behavior (Zhang, 2017b). The life-oriented approach can serve to shape policy decisions more efficiently and constructively by taking a broader view and then recording the interrelationships (Chikaraishi, 2017).

Though there exist many definitions of the term 'quality of life' (QOL), the prevailing one in recent years has been a multidimensional and interactive construct covering many aspects of an individual's environment and life (Schalock et al., 2008). Parts of the relevant literature assume that two factors important for QOL are social indicators and subjective well-being, which includes concepts such as negative and positive effects, happiness, and life satisfaction (Gilbert and Abdullah, 2004). In summary, individuals may find that they evaluate various aspects of life differently, thus necessitating an understanding of which decisions within the different domains of life result in improved QOL. Therefore, the question of how life decisions are correlated and how strongly they influence QOL requires further investigation (Xiong and Zhang, 2017).

Zhang (2017a) identified nine life domains relating to QOL: social network, health, leisure and tourism, education and learning, trip-making, job, residence, family budget, and family life. Within each domain, there is a corresponding set of life choices that can have a negative or positive impact on an individual's QOL (Xiong and Zhang, 2017). Any decision in one of the listed domains can arise from a different decision related to these domains while at the same time influencing further decisions (Zhang and Xiong, 2015). Several studies have demonstrated how satisfaction in each of these life domains contributes to general overall well-being (e.g., Cummins, 2005; Maia et al., 2016). However, the interdependencies among decisions in various life domains remain underinvestigated (Xiong and Zhang, 2017).

Research conducted in the field of life-oriented travel behavior is of particular interest in this context (Beige and Axhausen, 2017; Muromachi, 2017; Zhang and Van Acker, 2017). Such studies apply the life-oriented approach to examine the correlation between decisions in the field of mobility and those related to other stages of life. It has been found that mobility decisions are intertwined with a person's other life decisions (Beige and Axhausen, 2017). Zhang and Van Acker (2017) argue that in the longterm, not only do life decisions influence mobility behavior, but mobility behavior influences life decisions as well. By combining various research domains in mobility, research in life-oriented travel behavior can address the implications for not only transport policies, but also other sectors that intersect and require consideration in relation to mobility. Sustainable mobility and the question of car ownership have also been researched using a life-oriented approach (Beige and Axhausen, 2017; Delbosc and Nakanishi, 2017). With this broader contemplation, mobility issues can be analyzed more precisely and thus more productive solutions found (Zhang and Van Acker, 2017).

\section{Research Model and Hypothesis Development}

In combination with the TAM framework, we included the life-oriented approach to enrich the proposed research model as suggested by Rasouli and Timmermans (2017), due to single perspectives not being enough for comprehensive investigations. Adding extensions is intended to increase the contextspecific expressiveness and the degree of explanation of acceptance, and thereby travel behavior, thus granting a better understanding within the policy-making process. The proposed research model is illustrated in Figure 2. 
The extensions are clustered into four areas: life choices, subjective well-being, factors of travel quality, and life domains. To subclassify the research groups, the corresponding moderator variable of age is included as well.

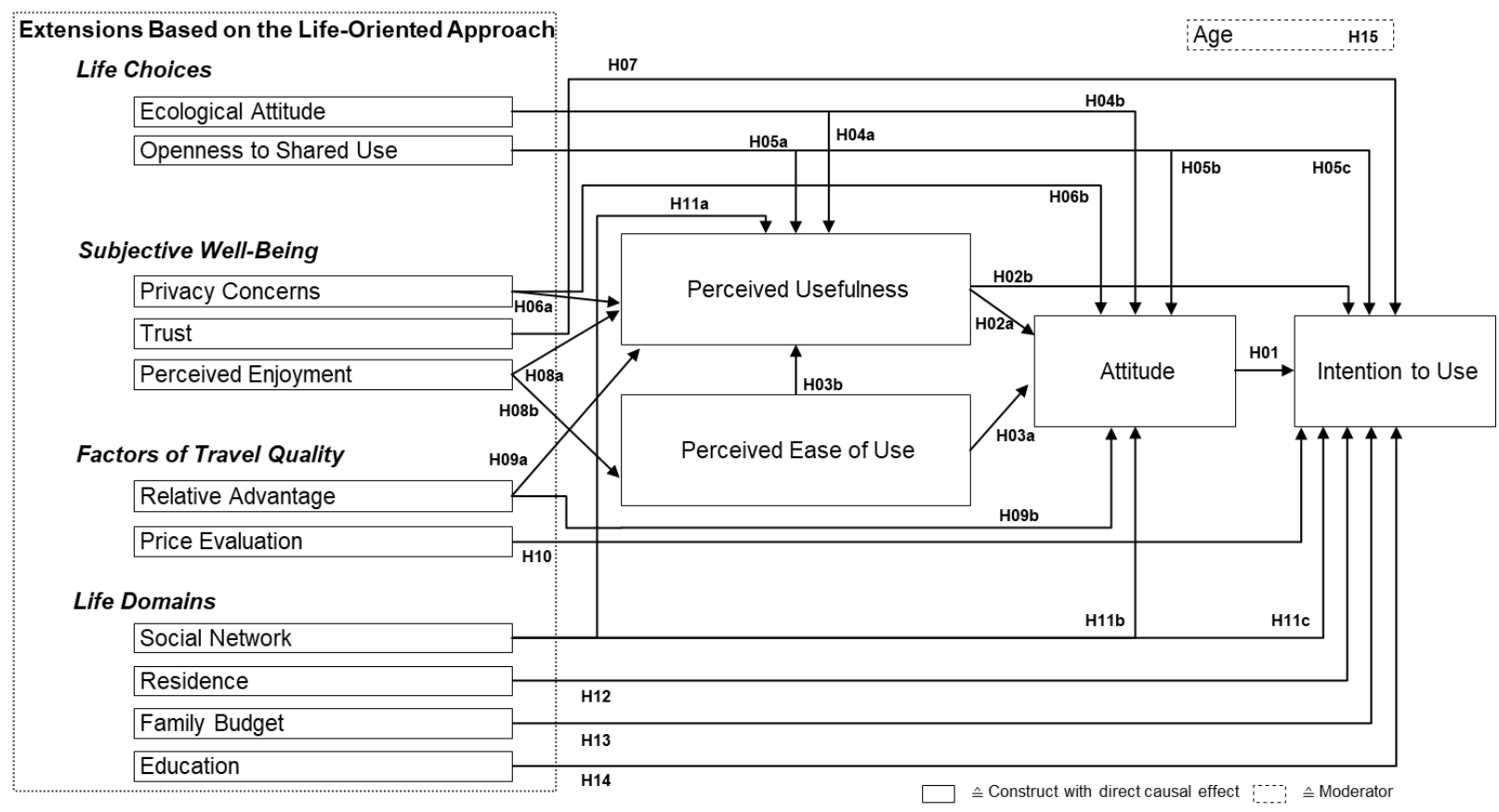

Figure 2. Proposed Research Model for Investigating SDPB Acceptance

\subsection{TAM}

As the research model is based on the original TAM, we conceptualize the acceptance of SDPBs from the end-user's point of view via the dependent constructs attitude and intention to use. (Venkatesh et al., 2003). Intention to use describes an individual's intent to actually ride a SDPB in the foreseeable future. This causal connection has already been demonstrated in other studies, to the extent an attitude can be observed to be an essential determinant of the intention to use (Nysveen et al., 2005). Thus, attitude transfers external influences to the intention to use and corresponds to the objectives of the model to be developed. This allows us to pose the following hypothesis:

H01: The more positive the attitude toward SDPBs, the greater the intention to use SDPBs.

TAM postulates that perceived usefulness and perceived ease of use are determinants of attitude. Furthermore, it assumes a direct positive influence of perceived usefulness on intention to use. In the present model, perceived usefulness is defined as how convinced a potential end-user is of the (future) usefulness of riding a SDPB. The transferability of the definition of perceived ease of use (Davis, 1989) from the business context to the consumer-specific one has been confirmed in many studies (Bruner II and Kumar, 2005; Nysveen et al., 2005; Pedersen and Nysveen, 2003; Wu and Wang, 2005). The cause-effect relationships between perceived usefulness and attitude put forth by Davis (1989), along with intention to use, are also assumed in the present acceptance model. It is inferred that perceived usefulness increases with perceived ease of use (Davis, 1989; Venkatesh et al., 2003). Therefore, we propose the following set of hypotheses:

H02a: The greater the perceived usefulness, the more favorable the attitude toward SDPBs.

H02b: The greater the perceived usefulness, the greater the intention to use SDPBs.

H03a: The greater the perceived ease of use, the more favorable the attitude toward SDPBs.

H03b: The greater the perceived ease of use, the greater the perceived usefulness of SDPBs. 


\subsection{Life Choices}

Life choices are fundamental within the life-oriented approach, as they correlate with QOL and depend on the life domains. Therefore, understanding life choices is important because people usually make several varying life choices under different conditions. We included two constructs - ecological attitude and openness to shared use - as decisions regarding these life choices may have an impact on SDPB acceptance (Ballús-Armet et al., 2014; Ozaki and Dodgson, 2010; Peters et al., 2011; Schaefers, 2013; Shaheen et al., 2012; Tussyadiah, 2015).

\subsubsection{Ecological Attitude}

The ecological attitude of potential end-users can be considered as a life choice because of the reliance on each individual to behave in an eco-friendly manner or not (Zhang, 2017a). Various scientific contributions have demonstrated how the decision to purchase a vehicle with hybrid drive depends largely on one's appreciation of ecological aspects (Ozaki and Dodgson, 2010; Peters et al., 2011). In addition, many users of shared services in the transport sector attach importance to the environmental benefits (Schaefers, 2013) of their transport decisions. Compared to other consumers, environmental enthusiasts are much more likely to use a "green" means of transport, such as public transport (Kahn, 2007).

In the case of the SDPB, public transport is combined with an environmentally friendly drive system, thanks to the electric-powered drive and the more emission-friendly driving style of an autonomous vehicle. It can help to replace other existing transportation options with a single integrative mode of transportation, curb excessive energy consumption, minimize traffic congestion, and moderate air pollution (Hars, 2015; Herminghaus, 2019). For those with high ecological awareness, SDPBs could be an attractive alternative to other vehicles. Due to their higher efficiency (shared and electric-powered drive), SDPBs can contribute significantly to fuel savings and improved utilization per person and thus to improving the environmental compatibility of public transport. Hence, we present the following two hypotheses:

H04a: The more pronounced a person's ecological attitude, the greater the perceived usefulness of SDPBs.

H04b: The more pronounced a person's ecological attitude, the better the attitude toward SDPBs.

\subsubsection{Openness to Shared Use}

The 'sharing economy' is a general term encompassing various developments that make it possible to share goods and services online (Puschmann and Alt, 2016). For cases such as Airbnb, extrinsic motivation exists because of inherent monetary compensation. On platforms where compensation is lower than the effort of sharing - or with no compensation whatsoever - the question of motivation becomes more difficult to assess (Norbutas and Corten, 2018). Studies on altruistic behavior maintain that such behavior is "contagious" (e.g., Yamagishi and Cook, 1993), with previous experiences and decisions influencing current behaviors. Furthermore, a specific life decision may arise from other decisions or also influence them (Zhang, 2017a). In the sharing economy, it is of particular interest whether the openness to shared use influences SDPB acceptance. Previous research has demonstrated, for example, that it can embody the acceptance of e-mobility (Fazel, 2013). Therefore, the SDPB as a shared vehicle will be a more attractive means of transport if there is a positive attitude toward the shared use of vehicles. We therefore propose the following set of hypotheses:

H05a: Openness to shared use has a positive influence on the perceived usefulness of SDPBs.

H05b: Openness to shared use has a positive influence on attitude toward SDPBs.

H05c: Openness to shared use has a positive influence on the intention to use SDPBs. 


\subsection{Subjective Well-Being}

It is well known that travelers can experience both positive as well as negative feelings while traveling (Mokhtarian and Salomon, 2001). Aiming to better understand this occurrence, the number of subjective well-being studies geared toward the analysis of travel behavior has been on the rise (e.g., Ettema et al., 2010; Smith, 2017; Wheatley, 2014; Zhang, 2009). Subjective well-being is concerned with a person's self-assessment of his/her individual condition (Diener et al., 1999). Therefore, we argue that the constructs that are closer to the area of subjective well-being research are a useful extension of the present research model and respond diligently to broaden the scope of existing acceptance models (Rasouli and Timmermans, 2017). We included three constructs - privacy concerns, trust, and perceived enjoyment - as each affect subjective well-being in a certain way and may impact the acceptance of SDPBs (e.g., Diener, 2000; K. M. Sheldon et al., 1996; Ye and Ho, 2019).

\subsubsection{Privacy Concerns}

One factor related to subjective well-being and influencing the acceptance of technological innovations is privacy concerns (Litman, 2015; Nasri and Charfeddine, 2012; Vijayasarathy, 2004; Ye and Ho, 2019). These relate to one's lack of ability to control and handle one's own information (Belanger et al., 2002; Phelps et al., 2000). In light of the increased connectivity of autonomous vehicles through information systems, drivers are particularly hesitant to use a vehicle technology that can reveal the vehicle's location at any time (Mahoney and O'Sullivan, 2013). This result is reinforced by the vulnerability of steering and control systems in modern cars to hacking attacks (Koscher et al., 2010). A recent study by Habeck et al., (2014) revealed that although a majority of new car buyers in the US consider car-related features to be an important criteria, nearly $50 \%$ of them are wary about using use car-related connected services due to the rise of privacy and digital security concerns, such as hacking incidents. Studies have shown that data protection concerns have a negative effect on the decisionmaking process and increase hesitancy (Nasri and Charfeddine, 2012; Phelps et al., 2000). We therefore argue that privacy concerns are negatively linked to attitudes toward using SDPBs and propose the following hypotheses:

H06a: Privacy concerns associated with SDPBs negatively influence their perceived usefulness.

H06b: Privacy concerns associated with SDPBs negatively influence attitude toward them.

\subsubsection{Trust}

In building a person's subjective well-being, trust remains a vital element (e.g., Diener, 2000; Dolan et al., 2008; Hudson, 2006). A SDPB can completely control steering, acceleration, and deceleration through its built-in autonomous system. Trust in such systems is generally considered to be an important factor for the acceptance of AD (Choi and Ji, 2015; Mayer et al., 1995; Verberne et al., 2012). Choi and Ji (2015) concluded that trust in the context of AD is represented by the following three dimensions: First, system transparency, which is defined as how the individual understands the operation of autonomous vehicles. Second, technical competence, meaning how individuals evaluate the overall performance of an autonomous vehicle from a technical perspective. Third, situation management, describing an individual's conviction in their ability to regain control in all situations at all times. We therefore propose the following hypothesis:

H07: The greater the trust in SDPBs, the greater the intention to use them.

\subsubsection{Perceived Enjoyment}

Enjoyment is related to subjective well-being and thus to the life-oriented approach (e.g.,Diener et al., 1997; Sheldon et al., 1996). In this case, perceived enjoyment describes the individual's level of intrinsic motivation to use a system solely for fun, rather than for performance improvement (Venkatesh 2000). Venkatesh and Bala (2008) mention that enjoyment does not increase the benefits of using a system; instead it reduces the difficulties individuals experience when interacting with a system and 
they enjoy the process itself. The positive effect of perceived enjoyment on perceived ease of use and attitude has also been observed in several other contexts (e.g., Kulviwat et al., 2007; Saadé and Bahli, 2005; Sun and Zhang, 2006; Venkatesh, 2000). Therefore, we can assume the following two hypotheses:

H08a: The greater the perceived enjoyment of using a SDPB, the greater its perceived usefulness.

H08b: The greater the perceived enjoyment of using a SDPB, the better its perceived ease of use.

\subsection{Travel Quality Factors}

The quality of one's travel behavior is important for both travelers and transport policy. Shorter travel times and lower travel costs most certainly indicate a boost in overall quality, i.e., more adept travel services (Zhang and Van Acker, 2017). Likewise, the option of multitasking, which includes listening to music, reading, or surfing the Internet also increases the quality of travel (e.g., Redmond and Mokhtarian, 2001; Zhang, 2009).

From the perspective of the life-oriented approach, determining which life decision is served corresponds with the quality of travel behavior. This quality can be associated with the life choice as well as its cost (e.g., travel time and costs) and its QOL (Zhang and Van Acker, 2017). Therefore, our proposed research model includes constructs related to travel quality-relative advantage and price evaluation - to investigate quality criteria depending on different domains. Each construct is related to travel quality and may influence the acceptance of SDPBs (Kulviwat et al., 2007; Rogers, 2010; Venkatesh et al., 2012; Zhang and Van Acker, 2017).

\subsubsection{Relative Advantage}

According to Rogers (2010), relative advantage is a characteristic of innovation, described as how an innovation is evaluated in comparison to its previous manifestation or idea. Kulviwat et al. (2007) identify the act of individuals rating an innovation as being more useful if it increases their perception of the innovation as more improved than its precursor. In addition, the researchers claim that, compared to an organizational context, the positively associated attitude to perform a behavior connects with the relative advantage, as consumers are willing to compare characteristics of innovations in decision-making. In the context of autonomous vehicles, a study by Schoettle and Sivak (2014) revealed that $57 \%$ of respondents had a positive attitude toward AD, mainly due to factors such as their reduced rate of accidents, lower fuel consumption and emissions, and potential to cut down on traffic jams and travel time. Therefore, we include here the following hypotheses:

H09a: The greater the perceived relative advantage of using SDPBs, the greater their perceived usefulness.

H09b: The greater the perceived relative advantage of using SDPBs, the more positive the attitude toward them.

\subsubsection{Price Evaluation}

With regard to travel quality factors, costs and prices are both mentioned as prime factors (Zhang and Van Acker, 2017), making this a suitable construct from the literature on price evaluation. Price evaluation is defined as a cognitive compromise between the cost of using a technology and its perceived benefits (Dodds et al., 1991). To determine a service or product's perceived value, the monetary price is most likely assessed jointly with the its quality (Zeithaml, 1988). Venkatesh et al. (2012) maintain that price evaluation is vital in explaining acceptance of consumer goods technologies, as consumers typically pay the cost of using a technology, noting, "price value is positive when the benefits of using a technology are perceived to be greater than the monetary cost and such price value has a positive impact on intention" (p. 5). Thus, we predict the following: 
H10: The higher the (positive) price evaluation, the greater the intention to use SDPBs.

\subsection{Life Domains}

The understanding of SDPB acceptance may be strengthened by integrating the life-oriented approach's life domains, as their interdependencies among the considered constructs as decisions in different areas of life have been confirmed by their impact on travel behavior (Xiong and Zhang, 2014; Zhang, 2014; Zhang and Van Acker, 2017). The proposed research model includes the domains of social network, residence, family budget, and education (Zhang, 2017a).

\subsubsection{Social Network}

Several studies in the transportation literature have demonstrated how social networks are important for a person's travel behavior and decisions (Sharmeen et al., 2014). Zhang (2017b) argues that one can perceive the social network as a life domain. Accordingly, we argue that in the context of the lifeoriented approach, one should account for the influence of the social environment when investigating the acceptance of a new mode of transport such as the SDPB. Research by Fisher and Price (1992), as well as Felden (2011), has demonstrated the social environment's influence on an innovation's adoption. Therefore, we included social network in the model as a subjective norm to address aspects of an individual's social network, enriching TAM with dimensions of the life-oriented approach. Bansal et al. (2016) examined the extent to which social factors influence adoption of AD, discovering that nearly $50 \%$ of respondents prefer to see friends, family members, or neighbors operate AD before they adopt it themselves. This confirms the relevance of the social environment and results in the following hypotheses:

H11a: The social network has a positive influence on the perceived usefulness of SDPBs.

H11b: The social network has a positive influence on attitude toward SDPBs.

H11c: The social network has a positive influence on the intention to use SDPBs.

\subsubsection{Residence}

Residence is an important domain influencing QOL and travel behavior (Xiong and Zhang, 2017). A recent study which coincides with this research context concluded that people living in cities with a high volume of traffic are more interested in AD and SDPBs than those from rural areas are (Misell, 2014). Lewis and Simmons (2012) also found that urban dwellers seem to be more attracted to shared services. This would suggest that people living in highly populated areas exhibit greater intention to use SDPBs. Therefore, we expect the following:

H12: The larger the area of residence in terms of number of inhabitants, the greater the intention to use SDPBs.

\subsubsection{Family Budget}

Due to a SDPB being more likely to emerge onto the market at a relatively low price compared to an $\mathrm{AD}$ vehicle, it is likewise likely to cost more than the current comparable means of transport. Therefore, it can be assumed that the moderator variable income will have a corresponding influence. For example, income could significantly influence the individual price-performance ratio and thus affect intention to use. The results of Kyriakidis et al.'s (2015) study reveal that the individuals with above average incomes would be more willing to purchase a more expensive proximate vehicle if it were equipped with automatic driving functions. Moreover, Zhang (2017b) contends that life-oriented decisions depend on the family budget. Altogether, this results in the following hypothesis:

H13: The higher the family budget, the greater the intention to use SDPBs. 


\subsubsection{Education}

Studies on the use of technologies and their adoption have already established that an individual's level of education can have a significant influence on a technology's acceptance (Czaja et al., 2006; Wang et al., 2008). With regard to sharing mobility, current research has emphasized that the more educated a person is, the greater his/her interest in joint activities is (e.g., Efthymiou et al., 2013). For example, carsharing users generally have higher levels of education (Witzke, 2016). In addition, Lewis and Simmons's (2012) findings suggest that both potential and current users of peer-to-peer carsharing are well educated, with the majority of users possessing a university degree. Hence, we pose the following hypothesis:

H14: The more educated a person is, the greater their intention to use SDPBs.

\subsection{Age as a Moderator}

According to Zhang's life-oriented approach (2017a, b), life decisions are interdependent and aspects such as place of residence, available budget, education, and the social network both determine and depend on life choices. On this basis, the research model can be applied to examine the correlations postulated, as well as with regard to the moderator variable age, allowing for derivations between young and older people.

The significant influence of age as a moderator has already been demonstrated in other acceptance studies. Venkatesh et al. (2003), for example, found that the intention to use new technologies decreases significantly with increasing age. With regard to the research context, Bansal et al.'s (2016) study indicates that older people are more reserved in their money-spending habits towards automated vehicles due to a fear that they will fail to learn how to use them and likewise have less confidence in new technologies.

The potential for certain customer segments to be more attracted to driverless vehicles was previously excluded from private vehicle use. Researchers argue that older and very young people in particular can be seen as early adopters of autonomous driving (Hedli, 2014; Minx and Dietrich, 2015). Furthermore, the carsharing sector tends to be more attractive to young people than to older ones (Shaheen and Cohen, 2013). Research has emphasized that the most prominent user group of peer-to-peer carsharing lies between the ages of 25 and 34 (Lewis and Simmons, 2012). Therefore, as far as the intention to use SDPBs, it is argued that age could moderate the casual effects within the proposed model:

H15: Age moderates influences that determine the intention to use SDPBs.

\section{$4 \quad$ Research Methodology}

\subsection{Measurement of Constructs}

The research model constructs described above were measured with items adapted to the research context, stemming from available literature. The relevant items were measured using a 7-step Likert scale ranging from 1 ("disagree completely") to 7 ("fully agree"). Only the moderator variable age, as well as the constructs residence, family budget, and education, were queried using a nominal scale. The theoretical constructs along with their operationalized items and related references are presented in the Appendix (Table A1).

\subsection{Data-Collection Procedure and Sample}

We designed an online questionnaire based directly on the research model by using the software SoSci Survey. The data was collected in September 2018 in Germany, where participants were recruited through direct acquisition after riding a local SDPB. The bus, produced by the French manufacturer EasyMile, was in service from July 13 to September 30, 2018. The bus itself had six seats and traveled at a speed of 15 kilometers per hour on a circuit about 1 kilometer long, with the entire route located 
on public roads. There was neither a steering wheel nor an accelerator pedal aboard in the bus, so no driver was needed for assistance. There was, however, one security escort on board, whose role was to intervene as necessary. No additional infrastructure was required for the bus, as it drove along a virtual line stored in the bus software. With the help of sensors, the bus could detect obstacles and signals on the road (SWEG, 2018).

In total, 271 participants were invited to take part in the survey. All incomplete questionnaires were sorted out, reducing the count to 268 participants. Of these, $49.6 \%$ were female and $43.2 \%$ were below the age of 35 . Furthermore, $3 \%$ stated their highest completed degree to be secondary school, $15 \%$ held a comprehensive school leaving certificate, $7 \%$ held a high school certificate qualifying for university admission, $44 \%$ had completed vocational training, and $31 \%$ had earned an academic degree. Monthly income varied among participants as follows: $31 \%$ below $€ 1,999 ; 34 \%$ between $€ 2,000$ and $€ 2,999 ; 22 \%$ between $€ 3,000$ and $€ 3,999 ; 10 \%$ between $€ 4,000$ and $€ 4,999$; and $3 \%$ over $€ 5,000$. Moreover, $22 \%$ of participants lived in small towns with fewer than 20,000 inhabitants; $34 \%$ lived in towns with 20,000 to 100,000 inhabitants; $24 \%$ lived in large towns with over 100,000 inhabitants; and $20 \%$ lived in rural areas. This mirrors the population distribution in Germany (Worldometers, 2019).

\subsection{Common Method Bias}

To counteract biases caused by data collection from a single informant, we employed various procedural remedies for common method variance (Podsakoff et al., 2012). These included a cover story with detailed descriptions and examples and the use of well-developed scales, which both decrease biases through ambiguous questions. We further motivated participants to respond accurately by telling them that their opinion is valued and that there are no wrong answers, which has been shown to decrease social desirability biases. Furthermore, to detect a common post hoc method bias, we applied Harman's single-factor test. We conducted an exploratory factor analysis including all measurement items, with no single factor emerging from the computation. Moreover, the results yield no such factor that accounts for most of the variance. Hence, we conclude that common method bias is not a threat for this investigation.

\section{$5 \quad$ Data Analysis and Results}

To test the theoretical model and our hypotheses, we used a structural equation modeling (SEM) approach. We chose the partial least squares (PLS) method because it places fewer demands on the sample and does not require a normal distribution (Ringle et al., 2012). We then used SmartPLS 3.0 for the PLS-based estimations. For calculations that were unavailable within the SmartPLS package, we employed SPSS Statistics 21.

The subsequent sections follow the two-step approach for SEM: first we assess the quality criteria of the measurement model, and then we analyze the structural model (Anderson and Gerbing, 1988).

\subsection{Measurement Validation}

We first assessed the fit of the research model and empirical data. The constructs were tested for content, convergent, and discriminant validity, with all constructs measured reflectively. All test results reported in Table 1 and in the Appendix (Table A2) are based upon the PLS estimation of the research model with the full data set.

We ensured content validity by using existing scales from related research that fit our theoretical constructs, in addition to having the questionnaire reviewed by academic experts in the pretest. Furthermore, three measures were evaluated to offer evidence of convergent validity. We inspected individual item reliability, composite construct reliability (CR), and average variance extracted (AVE). All items load on their respective constructs at above 0.70, indicating an acceptable level of individual item reliability (Gefen and Straub, 2005). In addition, the CR indicators lie between 0.89 and 0.97 , which is 
above the acceptable limit of 0.70 (Hulland, 1999). Convergent validity becomes an indication if the corresponding items of a construct converge. That being said, the AVE of each construct lies above the lower bound of 0.50 (Bhattacherjee and Premkumar, 2004). We also assessed discriminant validity to determine whether theoretically distinct concepts are also empirically distinct, thus inspecting the cross-loadings. As expected, we found that all items have higher loadings on their assigned construct than on any other construct (Appendix, Table A2) (Chin, 1998).

Table 1. Composite Reliability, Average Variance Extracted, and Inter-Construct Correlations

\begin{tabular}{|c|c|c|c|c|c|c|c|c|c|c|c|c|c|c|c|c|c|}
\hline & CR & AVE & 1 & 2 & 3 & 4 & 5 & 6 & 7 & 8 & 9 & 10 & 11 & 12 & 13 & 14 & 15 \\
\hline 1. Attitude & .89 & .62 & .79 & & & & & & & & & & & & & & \\
\hline 2. Ecological Attitude & .90 & .69 & .26 & .83 & & & & & & & & & & & & & \\
\hline 3. Education & n.a. & n.a. & .07 & .05 & n.a. & & & & & & & & & & & & \\
\hline 4. Family Budget & n.a. & n.a. & -.01 & .03 & .35 & n.a. & & & & & & & & & & & \\
\hline 5. Intention to Use & .96 & .83 & .67 & .29 & .05 & .08 & .91 & & & & & & & & & & \\
\hline 6. Openness to Shared Use & .91 & .77 & -.17 & -.14 & .01 & .03 & -.19 & .88 & & & & & & & & & \\
\hline 7. Privacy Concerns & .95 & .83 & -.17 & -.14 & -.05 & -.01 & -.20 & .19 & .91 & & & & & & & & \\
\hline 8. Price Evaluation & .94 & .89 & .28 & .28 & -.07 & .02 & .31 & -.19 & -.02 & .94 & & & & & & & \\
\hline 9. Perceived Enjoyment & .95 & .85 & .65 & .30 & .06 & .00 & .55 & -.16 & -.23 & .30 & .92 & & & & & & \\
\hline 10. Perceived Ease of Use & .95 & .83 & .52 & .22 & .08 & .06 & .49 & -.12 & -.09 & .20 & .51 & .91 & & & & & \\
\hline 11. Perceived Usefulness & .93 & .76 & .52 & .26 & -.02 & -.01 & .46 & -.12 & -.16 & .24 & .36 & .34 & .87 & & & & \\
\hline 12. Relative Advantage & .95 & .80 & .41 & .22 & -.05 & -.02 & .35 & -.07 & -.08 & .27 & .42 & .17 & .56 & .89 & & & \\
\hline 13. Residence & n.a. & n.a. & .06 & -.02 & .35 & .27 & .12 & -.16 & -.11 & -.01 & .03 & .11 & .09 & -.01 & n.a. & & \\
\hline 14. Social Network & .97 & .89 & .47 & .25 & -.10 & .04 & .47 & -.15 & -.14 & .25 & .37 & .24 & .46 & .41 & -.07 & .94 & \\
\hline 15. Trust & .97 & .90 & .58 & .24 & .10 & .02 & .53 & -.08 & -.19 & .23 & .61 & .50 & .41 & .33 & .01 & .34 & .95 \\
\hline
\end{tabular}

Note. AVE: average variance extracted; CR: composite reliability; bolded numbers: square root of AVE.

Moreover, we checked for the Fornell and Larcker (1981) criterion. We were able to confirm discriminant validity, as the AVE for each construct is higher than the shared variance with other constructs. In sum, the analysis of the measurement model suggested that it is acceptable and reliable.

\subsection{Structural Model}

We applied the PLS method to estimate the structural model. The bootstrapping re-sampling method was used therein to assess levels of the structural model significant enough, thus creating 1000 samples. The results of the PLS estimation are presented in Table 2, revealing that the model displays variance at a considerable level in all dependent constructs.

As can be observed, the results support the basic structure of TAM. We found a significant effect between attitude and intention to use, perceived usefulness and intention to use, perceived usefulness and attitude, perceived ease of use and attitude, as well as perceived ease of use and perceived usefulness.

In regard to the life-oriented approach, we found no significant influence of life choices on constructs of the technological acceptance model. For subjective well-being, we found a significant influence of perceived enjoyment on perceived ease of use, of trust on intention to use, and of privacy concerns on perceived usefulness. The results support the hypothesized constructs of the factors of travel quality dimension. Relative advantage exhibits a significant impact on both perceived usefulness and attitude. In additional, price evaluation displays a significant influence on intention to use. Concerning the constructs of the life domain, we found a significant influence of social network on perceived usefulness, attitude, and intention to use. Moreover, we found a significant influence of both residence and family budget on intention to use. 
Table 2. Estimation of the Structural Model

\begin{tabular}{|c|c|c|c|c|}
\hline \multirow[b]{2}{*}{ Independent Variable } & \multicolumn{4}{|c|}{ Dependent Variable } \\
\hline & $\begin{array}{l}\text { Perceived Ease } \\
\text { of Use }\end{array}$ & $\begin{array}{l}\text { Perceived } \\
\text { Usefulness }\end{array}$ & Attitude & $\begin{array}{l}\text { Intention } \\
\text { to Use }\end{array}$ \\
\hline \multicolumn{5}{|l|}{ Technology Acceptance Model } \\
\hline Attitude (H01) & & & & $0.40 * * *$ \\
\hline Perceived Usefulness (H02a, b) & & & $0.21 * * *$ & $0.06^{*}$ \\
\hline Perceived Ease of Use (H03a, b) & & $0.21 * * *$ & $0.35^{* * *}$ & \\
\hline \multicolumn{5}{|l|}{ Life Choices } \\
\hline Ecological Attitude (H04a, b) & & 0.07 & 0.03 & \\
\hline Openness to Shared Use (H05a, b, c) & & -0.01 & -0.06 & -0.04 \\
\hline \multicolumn{5}{|l|}{ Subjective Well-Being } \\
\hline Privacy Concerns (H07a, b) & & $-0.07 *$ & -0.05 & \\
\hline Trust (H07) & & & & $0.19^{* * *}$ \\
\hline Perceived Enjoyment (H08a, b) & $0.51 * * *$ & -0.05 & & \\
\hline \multicolumn{5}{|l|}{ Factors of Travel Quality } \\
\hline Relative Advantage (H09a, b) & & $0.43 * * *$ & $0.14 * * *$ & \\
\hline Price Evaluation (H10) & & & & $0.08^{* *}$ \\
\hline \multicolumn{5}{|l|}{ Life Domains } \\
\hline Social Network (H11a, b, c) & & $0.22^{* * *}$ & $0.21 * * *$ & $0.16^{* * *}$ \\
\hline Residence (H12) & & & & $0.08 *$ \\
\hline Family Budget (H13) & & & & $0.06^{*}$ \\
\hline Education (H14) & & & & -0.02 \\
\hline$R$-squared & 0.27 & 0.43 & 0.47 & 0.52 \\
\hline
\end{tabular}

Note. ${ }^{* * *} p<.01 ; * * p<.05 ; * p<.10$.

\subsection{Age Differences}

To determine how SDPB acceptance compares across different generations of adopters, we conducted a subgroup analysis. Based on split samples, we performed multi-group analyses using a WelchSatterthwaite test to assess whether the path coefficients are significantly different between the groups. Table 3 presents the results of these analyses, revealing a significantly different path estimation for perceived usefulness on intention to use, perceived ease of use on perceived usefulness, ecological attitude on perceived usefulness, price evaluation on intention to use, and residence on intention to use. 
Table 3. Results of the Sub-Group Analysis

\begin{tabular}{|c|c|c|c|c|}
\hline Path & & Young & Elders & young - elders \\
\hline H01: & Attitude $\rightarrow$ Intention to Use & $0.45^{* * *}$ & $0.38 * * *$ & 0.07 \\
\hline H02a: & Perceived Usefulness $\rightarrow$ Attitude & $0.25^{*}$ & $0.24 * * *$ & 0.01 \\
\hline H02b: & Perceived Usefulness $\rightarrow$ Intention to Use & -0.07 & $0.12 *$ & $0.19 *$ \\
\hline H03a: & Perceived Ease of Use $\rightarrow$ Attitude & $0.23 *$ & $0.39 * * *$ & 0.16 \\
\hline H03b: & Perceived Ease of Use $\rightarrow$ Perceived Usefulness & $0.44 * * *$ & 0.11 & $0.34 * *$ \\
\hline H04a: & Ecological Attitude $\rightarrow$ Attitude & 0.13 & -0.01 & 0.14 \\
\hline H04b: & Ecological Attitude $\rightarrow$ Perceived Usefulness & -0.10 & $0.17 *$ & $0.27 * *$ \\
\hline H05a: & Openness to Shared Use $\rightarrow$ Intention to Use & -0.03 & -0.07 & 0.05 \\
\hline H05b: & Openness to Shared Use $\rightarrow$ Attitude & 0.01 & -0.08 & 0.10 \\
\hline H05c: & Openness to Shared Use $\rightarrow$ Perceived Usefulness & -0.05 & 0.03 & 0.08 \\
\hline H06а: & Privacy Concerns $\rightarrow$ Perceived Usefulness & $-0.13^{*}$ & -0.03 & 0.10 \\
\hline H06b: & Privacy Concerns $\rightarrow$ Attitude & -0.06 & -0.04 & 0.02 \\
\hline H07: & Trust $\rightarrow$ Intention to Use & $0.26 * *$ & $0.17 * *$ & 0.09 \\
\hline H08a: & Perceived Enjoyment $\rightarrow$ Perceived Usefulness & $-0.20 * *$ & 0.02 & 0.22 \\
\hline H08b: & Perceived Enjoyment $\rightarrow$ Perceived Ease of Use & $0.50 * * *$ & $0.53 * * *$ & 0.03 \\
\hline H09a: & Relative Advantage $\rightarrow$ Attitude & $0.16^{*}$ & 0.10 & 0.06 \\
\hline H09b: & Relative Advantage $\rightarrow$ Perceived Usefulness & $0.55 * * *$ & $0.39 * * *$ & 0.16 \\
\hline H10: & Price Evaluation $\rightarrow$ Intention to Use & -0.06 & $0.12 * *$ & $0.18^{*}$ \\
\hline H11a: & Social Network $\rightarrow$ Intention to Use & $0.15^{*}$ & $0.14^{* *}$ & 0.01 \\
\hline H11b: & Social Network $\rightarrow$ Attitude & $0.15^{*}$ & $0.23 * * *$ & 0.07 \\
\hline H11c: & Social Network $\rightarrow$ Perceived Usefulness & $0.24 * * *$ & $0.21 * * *$ & 0.03 \\
\hline H12: & Residence $\rightarrow$ Intention to Use & $0.19 * *$ & 0.02 & $0.17 *$ \\
\hline H13: & Family Budget $\rightarrow$ Intention to Use & 0.05 & $0.09 *$ & 0.04 \\
\hline H14: & Education $\rightarrow$ Intention to Use & -0.09 & -0.02 & 0.07 \\
\hline
\end{tabular}

Note. Significance values of the path difference | young - elders $\mid$ are based on a Welch-

Satterthwaite test (two-sided), $* * * p<.01 ; * * p<.05 ; * p<.10$.

\section{$6 \quad$ Discussion and Implications}

In the following, we explain and discuss the general results of this study in the context of existing literature and our research objectives, especially with regard to the differences between younger and older individuals. We also interpret the corresponding consequences for policy.

\subsection{SDPB Acceptance Criteria}

\subsubsection{TAM}

The results indicate that all postulated correlations within TAM can be confirmed and directly connected along the lines of existing literature on technology acceptance (e.g., Choi and Ji, 2015; Davis et al., 1989). The influence of perceived usefulness on attitude toward use and intention to use SDPBs can be explained by the participants' recognition of SDPBs as a useful future transport option. The 
influence of perceived ease of use on perceived usefulness and attitude toward use suggests that respondents expect SDPBs to be usable with minimal effort in the future.

Hence, an implication for policymakers is to prioritize the usefulness and simplicity of SDPBs through targeted influence in the technological development of future mobility services. Policies can also positively influence the formation of attitudes. For example, marketing campaigns could champion the advantages of SDPBs, promoting them as offering more flexible schedules or lower energy consumption than typical buses.

\subsubsection{Life Choices}

The life choices included - ecological attitude and openness to shared use-received only partial support and therefore require further investigation. However, stemming on our hypothesis derivation results, we still maintain that these components may influence individual acceptance. There could be several explanations for why the choice to live a more eco-friendly lifestyle does not have a statistically significant influence on perceived usefulness in the present study. One reason could be that the public does not yet fully trust the sustainability of electric mobility. For example, studies have shown that if the electricity for electric vehicles is generated by coal-fired power plants, $\mathrm{CO}_{2}$ emissions are the same as or even higher than those of conventionally powered vehicles (Hacker et al., 2009). Another factor could be that although electric vehicles are virtually emission-free in terms of local operation, their entire lifecycle (i.e., production, provision of energy for use, usage, maintenance, disposal) should be taken into account (Peters et al., 2012). Against this background, there may still be doubts among the population indicating the need for a transparent resolution. We also failed to find a statistically significant effect of openness to shared use on perceived usefulness, attitude, or intention to use, which could indicate that respondents do not assume that sharing rides with others while traveling via SDPB entails a certain level of unacceptability or inflexibility. Nevertheless, policymakers should still enforce the idea that availability of transport will not suffer as a result of sharing, especially as SDPBs have more flexible operating patterns than human-powered buses do (e.g., due no time dependencies on human resources). Furthermore, it could still be beneficial to highlight the more sustainable footprint of SDPBs, as previous research has successfully demonstrated the influence of ecological attitude and openness to shared use on the acceptance of sustainable innovations (e.g., Averdung and Wagenfuehrer, 2011; Fazel, 2013).

\subsubsection{Subjective Well-Being}

With regard to subjective well-being, our results reveal that perceived enjoyment has an influence on perceived ease of use, which corresponds with the research of, e.g., Venkatesh (2000) and Saadé and Bahli (2005). This means that as pleasure increases, so does SDPB acceptance. However, studies have also shown that $\mathrm{AD}$ might reduce driving pleasure, thus limiting some individuals' desire to use such vehicles in the first place (Kyriakidis et al., 2015; Pakusch et al., 2018a; Rödel et al., 2014). With SDPBs, the enjoyment must be evoked in a different manner. Policymakers should therefore ensure that riding SDPBs would be a pleasurable experience - for example, by integrating various entertainment functions. Policymakers would do well to support this area of research in further exploring how to maximize enjoyment. In addition, the study results indicate that trust displays a positive effect on the intention to use SDPBs, which is in line with Choi and Ji (2015). Policymakers must work to ensure that the general public understands the technology behind SDPBs, offering relevant information in a transparent and easily accessible way. Explanations of how the system makes decisions can also be important in this context. Such measures could lead to greater trust and thus bolster acceptance. In accordance with various other studies (e.g., Nasri and Charfeddine, 2012; Vijayasarathy, 2004), the negative influence of privacy concerns on perceived usefulness could be confirmed in our research. Given that privacy concerns can adversely affect the decision-making process (Nasri and Charfeddine, 2012; Phelps et al., 2000), policymakers must find solutions that protect the data rights of every individual. 


\subsubsection{Travel Quality Factors}

Our study results also confirm that travel quality factors influence SDPB acceptance. In line with Kulviwat et al. (2007) and Lin (2011), we found that relative advantage influences both perceived usefulness and attitude toward using SDPBs. As the relative advantage construct describes the improvement of an innovative technology over its predecessor, it can be deduced from the results that policies should emphasize the benefits of SDPBs compared to today's transportation possibilities. These could include their sustainability or their ability to make road traffic safer by eliminating human error.

The proposed influence of pricing on intention to use can also be confirmed by the study results: the better the price evaluation, the greater the intention to use. Policies should therefore ensure that future SDPB trips are affordable for the general public, even if the necessary technology still exceeds today's manufacturing prices (Litman, 2015). To do so, policies could be put in place to subsidize either the production process or the cost of SDPB tickets, which might otherwise be more expensive than conventional transport.

\subsubsection{Life Domains}

The results regarding the life domains suggest that the hypotheses regarding social network, residence, and family budget can all be confirmed. Various other studies have also corroborated the influence of the social network (e.g., Nysveen et al., 2005; Pedersen, 2005; Sharmeen et al., 2014). To increase SDPB acceptance, policymakers should therefore identify promoters who can act as public presence pioneers and supporters of the SDPB to positively influence the social environment. Various communication strategies should be pursued, focusing on using simple and straightforward statements to communicate the advantages of AD and SDPBs (Thorpe and Motwani, 2017). Policies should also ensure that everyone has easy access to objective information on SDPBs. Doing so could have a constructive influence on social networks and thus increase general acceptance.

Furthermore the results reveal that those residing in larger cities exhibit greater intention to use PDSBs than those living in smaller areas, consistent with the results of Misell (2014) and Lewis and Simmons (2012). Hence, policymakers should ensure that SDPBs are first established in larger cities, as their residents are typically more receptive to SDPB use than those living in the countryside. Only afterwards should they implement policies supporting the expansion to more rural regions, as they can then build on the success of SDPBs in cities. That the size of the family budget has an impact on the intention to use fits in broadly with the findings of Kyriakidis et al. (2015). Policymakers should therefore consider one of the following two options: either ensure that introductory prices are affordable enough for the masses or implement a campaign targeting higher income families and individuals who can afford more expensive ticket prices. Either scenario can achieve increased acceptance and thus contribute to a rapid dissemination of the technology.

\subsection{Age-Related Differences}

Age was found to have a significant moderating effect in certain cases, indicating that the travel behavior of young people is different than that of older people in many respects.

First, the results display a statistically significant distinction between the young and elderly in terms of the effect of perceived usefulness on intention to use. While young users' perceived usefulness of SDPBs is not significantly associated with the intention to use them, a positive relationship is present in the case of the elderly group. Hence, if policymakers want to target young people, focusing solely on perceived usefulness would be unlikely to result in increased intention to use SDPBs. In fact, our estimation reveals a small negative effect on the young user group. Although this effect is small and insignificant from a substantive point of view (Lohmöller, 2013), it is still quite surprising because it contradicts the vast majority of existing technology acceptance research (Wu and Lederer, 2009), providing an interesting avenue for further research. In contrast, a specific focus on perceived usefulness would be promising for targeting older people, as our results indicate a positive significant correlation for their case. Policymakers are therefore urged to instead foster a positive influence on the atti- 
tudes of young people, as attitude is the most important influencer of their intention to use SDPBs. Without such initiatives, the overall acceptance of this group could remain substantially below its potential.

Second, the results demonstrate a statistically significant difference between young and old people in terms of the relationship between perceived ease of use and perceived usefulness. Young people particularly value SDPBs for their simplicity and convenience, which translates into greater usefulness for them; however, this effect is less pronounced in older people. This means that policymakers can focus on ease of use if they want young people in particular to consider SDPB use for their future travels. Policymakers are therefore encouraged to develop solutions simplifying the use of SDPBs - for example, by developing mobile applications that assist in trip planning within a transit ecosystem.

Third, the study reveals a statistically significant difference between the age groups within the construct of ecological attitude, as its interdependency is positively significant for the elderly, while no significant relationship was found for younger people. Therefore, if policymakers want to change the travel behavior of young people, the campaign implemented should not be based on environmental factors but instead focus on other features found to have a significant association with the intention to use. However, if the aim is to appeal to older people, statements regarding eco-friendliness could be effective, as sustainably living elderly people rate the perceived usefulness of SDPBs higher and therefore exhibit greater intention to use SDPBs.

Fourth, the results demonstrate a statistically significant difference among the age groups considered in terms of the relationship between price evaluation and intention to use. While a generally positive correlation of effects had been confirmed, the results indicate that price evaluation has no significant influence on young people's intention to use. It can therefore be concluded that young people tend to be less concerned about the pricing of innovative mobility concepts. Older people, on the other hand, display a desired price that barely differs from today's comparable means of transport. It can be assumed that this age group is unwilling to pay a premium, even if for an innovative solution. Hence, in case of a future price premium, policymakers should positively influence the SDPB acceptance of older people by subsidizing the price for tickets, while for younger people this may be not necessary.

Finally, the results demonstrate a statistically significant difference between young and old people in relation to the association between place of residence and intention to use. Young people who live in larger cities display greater intention to use SDPBs, whereas for older ones, intention to use seems to be independent of where they live. This finding also helps policymakers better define a potential target group for SDPB introduction: in the ramp-up phase they should concentrate on communication strategies targeting young people in bigger cities, then adjusting their strategy in the long-run to rural regions.

\section{Conclusion}

The SDPB as a future smart mobility service has the potential to shift travel behavior to become more sustainable. Only with widespread acceptance can such innovative technologies result in market success. Our work developed a research model based on TAM and the life-oriented approach to study young people's acceptance of SDPBs as compared to older people. Life choices, subjective wellbeing, factors of travel quality, and life domains were found to affect SDPB acceptance with some differences based on age.

The study's results study indicate that policymakers must consider a wide range of acceptance factors (e.g., price evaluation, ecological attitude, place of residence), particularly when targeting different age groups, to ensure the broad acceptance and thus rapid dissemination of SDPBs. The specific results reported within support policymakers in shaping future travel behavior to be more environmentally friendly.

When interpreting the results, one should take into account the following limitations: (1) As the study was conducted in a European country, the generalization of results is limited to the respective countryspecific characteristics (Germany is a wealthy country with a high proportion of the population living 
in cities and a population density of roughly 237 inhabitants per square kilometer) (Worldometers, 2019). Therefore, future endeavors should replicate this research in other geographic areas to enhance the predictive power of the proposed research model. (2) A participant's experience with SDPBs is likely to bias the sample. However, Nordhoff et al. (2016) emphasize that acceptance research on selfdriving technologies is constrained by limited user experience. Therefore, our sample is especially important for studying SDPB acceptance, as the results rely on participants with real user experience. In this regard, TAM has been demonstrated to be suitable for predicting the acceptance of future technologies, particularly in the introduction stage (Davis and Venkatesh, 2004). Nonetheless, future research could employ models such as TAM2, TAM3, or UTAUT to validate our results. (3) In our case, the SDPB was deployed in a specific geographical area. As user experience might be influenced by factors particular to the location (Davis and Venkatesh, 2004), long-term field studies in different scenarios could provide further insights into the acceptance of such sustainable modes of transportation. (4) Previous research has used access to a driver's license to separate age groups (e.g., Stark et al., 2015). However, due to ethical restrictions, this study only included participants over the age of 18 . We therefore suggest that future research include participants below driving age for comparison. (5) Finally, as our research follows a quantitative research approach, we suggest employing qualitative research approaches, e.g., interviews, to substantiate and further examine this study's results.

\section{References}

Ajzen, I., 1991. The theory of planned behavior. Organ. Behav. Hum. Decis. Process. 50, 179-211.

Alemi, F., Circella, G., Handy, S., Mokhtarian, P., 2018. What influences travelers to use Uber? Exploring the factors affecting the adoption of on-demand ride services in California. Travel Behav. Soc. 13, 88-104. https://doi.org/10.1016/j.tbs.2018.06.002

Anderson, J.C., Gerbing, D.W., 1988. Structural Equation Modeling in Practice: A Review and Recommended Two-Step Approach. Psychol. Bull. 103, 411-423.

Arshad, M., Bhat, S.A., 2013. Global Ageing Trends: A Sociological Perspective. Int. J. Curr. Res. Acad. Rev. 1, 55-64.

Averdung, A., Wagenfuehrer, D., 2011. Consumers acceptance, adoption and behavioural intentions regarding environmentally sustainable innovations. J. Bus. Manag. Econ. 2, 98-106.

Ballús-Armet, I., Shaheen, S.A., Clonts, K., Weinzimmer, D., 2014. Peer-to-peer carsharing: Exploring public perception and market characteristics in the San Francisco Bay area, California. Transp. Res. Rec. 2416, 27-36.

Bansal, P., Kockelman, K.M., Singh, A., 2016. Assessing public opinions of and interest in new vehicle technologies: An Austin perspective. Transp. Res. Part C Emerg. Technol. 67, 1-14.

Beige, S., Axhausen, K.W., 2017. The dynamics of commuting over the life course: Swiss experiences. Transp. Res. Part A Policy Pract. 104, 179-194.

Beige, S., Axhausen, K.W., 2012. Interdependencies between turning points in life and long-term mobility decisions. Transportation 39, 857-872.

Beige, S., Axhausen, K.W., 2008. Long-term and mid-term mobility decisions during the life course: Experiences with a retrospective survey. IATSS Res. 32, 16-33. https://doi.org/10.1016/S03861112(14)60206-5

Beiker, S.A., 2012. Legal aspects of autonomous driving. St. Cl. L. Rev. 52, 1145-1561.

Belanger, F., Hiller, J.S., Smith, W.J., 2002. Trustworthiness in electronic commerce: the role of privacy, security, and site attributes. J. Strateg. Inf. Syst. 11, 245-270. https://doi.org/10.1016/S0963-8687(02)00018-5

Bernhart, W., Kaise, H., Ohashi, Y., Schönberg, T., Schilles, L., 2018. Reconnecting the rural Autonomous driving as a solution for non-urban mobility [WWW Document]. URL https://www.rolandberger.com/de/Publications/Reconnecting-the-rural-Autonomous- 
driving.html (accessed 5.11.18).

Bertoncello, M., Wee, D., 2015. Ten ways autonomous driving could redefine the automotive world [WWW Document]. URL https://www.mckinsey.com/industries/automotive-and-assembly/ourinsights/ten-ways-autonomous-driving-could-redefine-the-automotive-world (accessed 11.18.18).

Best, H., Lanzendorf, M., 2005. Division of labour and gender differences in metropolitan car use: an empirical study in Cologne, Germany. J. Transp. Geogr. 13, 109-121. https://doi.org/10.1016/j.jtrangeo.2004.04.007

Bhattacherjee, A., Premkumar, G., 2004. Understanding Changes in Belief and Attitude Toward Information Technology Usage: A Theoretical Model and Longitudinal Test. MIS Q. 28, 229254.

Brendel, A.B., Lichtenberg, S., Nastjuk, I., Kolbe, L., 2017. Adapting Carsharing Vehicle Relocation Strategies for Shared Autonomous Electric Vehicle Services, in: Thirty Eighth International Conference on Information Systems, pp. 1-20.

Brown, A., Gonder, J., Repac, B., 2014. An analysis of possible energy impacts of automated vehicles, in: Road Vehicle Automation. Springer, pp. 137-153.

Bruner II, G.C., Kumar, A., 2005. Explaining consumer acceptance of handheld Internet devices. J. Bus. Res. 58, 553-558.

Buehler, R., Nobis, C., 2010. Travel Behavior in Aging Societies: Comparison of Germany and the United States. Transp. Res. Rec. J. Transp. Res. Board 1, 62-70. https://doi.org/10.3141/2182-09

Chatterjee, K., Scheiner, J., 2015. Understanding changing travel behaviour over the life course: Contributions from biographical research, in: 14th International Conference on Travel Behaviour Research, pp. 19-23.

Chikaraishi, M., 2017. Mobility of the Elderly, in: Life-Oriented Behavioral Research for Urban Policy. Springer Japan, Tokyo, pp. 267-291. https://doi.org/10.1007/978-4-431-56472-0_10

Chin, W.W., 1998. Commentary: Issues and Opinion on Structural Equation Modeling. MIS Q. 22, $7-$ 16.

Choi, J.K., Ji, Y.G., 2015. Investigating the importance of trust on adopting an autonomous vehicle. Int. J. Hum. Comput. Interact. 31, 692-702.

Clark, B., Chatterjee, K., Melia, S., 2016. Changes to commute mode: The role of life events, spatial context and environmental attitude. Transp. Res. Part A Policy Pract. 89, 89-105.

Cummins, R.A., 2005. The domains of life satisfaction: An attempt to order chaos, in: Citation Classics from Social Indicators Research. Springer, pp. 559-584.

Czaja, S.J., Charness, N., Fisk, A.D., Hertzog, C., Nair, S.N., Rogers, W.A., Sharit, J., 2006. Factors predicting the use of technology: findings from the Center for Research and Education on Aging and Technology Enhancement (CREATE). Psychol. Aging 21, 333-352.

Davis, F.D., 1989. Perceived Usefulness, Perceived Ease Of Use, And User Acceptance. MIS Q. 13, 319-339. https://doi.org/10.2307/249008

Davis, F.D., Bagozzi, R.P., Warshaw, P.R., 1992. Extrinsic and Intrinsic Motivation to Use Computers in the Workplace. J. Appl. Soc. Psychol. 22, 1111-1132. https://doi.org/10.1111/j.15591816.1992.tb00945.x

Davis, F.D., Bagozzi, R.P., Warshaw, P.R., 1989. User acceptance of computer technology: a comparison of two theoretical models. Manage. Sci. 35, 982-1003.

Davis, F.D., Venkatesh, V., 2004. Toward preprototype user acceptance testing of new information systems: implications for software project management. IEEE Trans. Eng. Manag. 51, 31-46.

Delbosc, A., 2017. Delay or forgo? A closer look at youth driver licensing trends in the United States and Australia. Transportation 44, 919-926. https://doi.org/10.1007/s11116-016-9685-7

Delbosc, A., Currie, G., 2014. Changing demographics and young adult driver license decline in 
Melbourne, Australia (1994-2009). Transportation 41, 529-542.

Delbosc, A., Nakanishi, H., 2017. A life course perspective on the travel of Australian millennials. Transp. Res. Part A Policy Pract. 104, 319-336. https://doi.org/10.1016/j.tra.2017.03.014

Diener, E., 2000. Subjective well-being: The science of happiness and a proposal for a national index. Am. Psychol. 55, 34-43. https://doi.org/10.1037/0003-066X.55.1.34

Diener, E., Suh, E., Oishi, S., 1997. Recent findings on subjective well-being. Indian J. Clin. Psychol. $24,25-41$.

Diener, E., Suh, E.M., Lucas, R.E., Smith, H.L., 1999. Subjective Weil-Being: Three Decades of Progress. Psychol. Bull. 125, 276-302. https://doi.org/10.1006/pupt.1998.0157

Dodds, W.B., Monroe, K.B., Grewal, D., 1991. Effects of price, brand, and store information on buyers' product evaluations. J. Mark. Res. 28, 307-319.

Dolan, P., Peasgood, T., White, M., 2008. Do we really know what makes us happy? A review of the economic literature on the factors associated with subjective well-being. J. Econ. Psychol. 29, 94-122. https://doi.org/10.1016/j.joep.2007.09.001

Dykstra, P.A., van Wissen, L.J.G., 1999. Introduction: The Life Course Approach as an Interdisciplinary Framework for Population Studies, in: Population Issues: An Interdisciplinary Focus, pp. 1-22. https://doi.org/10.1007/978-94-011-4389-9_1

Efthymiou, D., Antoniou, C., Waddell, P., 2013. Factors affecting the adoption of vehicle sharing systems by young drivers. Transp. Policy 29, 64-73. https://doi.org/10.1016/j.tranpol.2013.04.009

Ettema, D., Gärling, T., Olsson, L.E., Friman, M., 2010. Out-of-home activities, daily travel, and subjective well-being. Transp. Res. Part A Policy Pract. 44, 723-732.

Eugensson, A., Brännström, M., Frasher, D., Rothoff, M., Solyom, S., Robertsson, A., 2013. Environmental, safety, legal and societal implications of autonomous vehicles, in: Proceedings of the International Technical Conference on the Enhanced Safety of Vehicles (ESV), pp. 1-15.

Fatmi, M.R., Habib, M.A., 2016. Longitudinal Vehicle Transaction Model: Assessment of Lead and Lagged Effects of Longer-Term Changes and Life-Cycle Events. Transp. Res. Rec. 2566, 11-21.

Fazel, L., 2013. Akzeptanz von Elektromobilität Entwicklung und Validierung eines Modells unter Berücksichtigung der Nutzungsform des Carsharing. Springer Gabler, München. https://doi.org/10.1007/978-3-658-02746-9

Felden, C., 2011. Characteristics of XBRL adoption in Germany. J. Manag. Control 22, 161-186. https://doi.org/10.1007/s00187-011-0134-7

Fisher, R.J., Price, L.L., 1992. An Investigation into the Social Context of Early Adoption Behavior. J. Consum. Res. 19, 477-486. https://doi.org/10.1086/209317

Fornell, C., Larcker, D.F., 1981. Structural Equation Models with Unobservable Variables and Measurement Error: Algebra and Statistics. J. Mark. Res. 18, 382-388. https://doi.org/10.1177/002224378101800313

Freund, A.M., Ritter, J.O., 2009. Midlife crisis: A debate. Gerontology 55, 582-591.

Gefen, D., Straub, D., 2005. A Practical Guide to Factorial Validity Using PLS-Graph: Tutorial and Annotated Example. Commun. Assoc. Inf. Syst. 16, 91-109.

Gilbert, D., Abdullah, J., 2004. Holidaytaking and the sense of well-being. Ann. Tour. Res. 31, 103121.

Habeck, A., Newman, J., Bertoncello, M., Kässer, M., Weig, F., Hehensteiger, M., Hölz, J., Plattfaut, R., Wegner, C., Guminski, M., Yan, Z., 2014. Connected car, automotive value chain unbound [WWW Document]. URL https://www.sas.com/images/landingpage/docs/3_McKinsey_John_ Newman_Connected_Car_Report.pdf (accessed 1.13.19).

Hacker, F., Harthan, R., Matthes, F., Zimmer, W., 2009. Environmental impacts and impact on the electricity market of a large scale introduction of electric cars in Europe - Critical Review of 
Literature. ETC/ACC Tech. Pap. 4, 56-90.

Hars, A., 2015. Self-Driving Cars: The Digital Transformation of Mobility, in: Marktplätze Im Umbruch. Springer Vieweg, Berlin, Heidelberg, pp. 539-549. https://doi.org/10.1007/978-3-66243782-7_57

Hedli, L., 2014. Why Self-Driving Cars Will Change Retirement - Older Adults Who Would Otherwise Be Stuck at Home May Be Early Adopters [WWW Document]. URL https://www.wsj.com/articles/why-self-driving-cars-will-change-retirement-1413147945 (accessed 1.13.19).

Herminghaus, S., 2019. Mean field theory of demand responsive ride pooling systems. Transp. Res. Part A Policy Pract. 119, 15-28.

Hirschl, B., Konrad, W., Scholl, G., 2003. New concepts in product use for sustainable consumption. J. Clean. Prod. 11, 873-881.

Hiscock, J., 2000. Market Research: How to separate all the shades of grey - To target the grey market, you must first understand its structure [WWW Document]. URL https://www.campaignlive.co.uk/article/market-research-separate-shades-grey-target-greymarket-first-understand-its-structure/72339 (accessed 1.10.19).

Högg, R., 2010. Erweiterung und Evaluation des Technologieakzeptanzmodells zur Anwendung bei mobilen Datendiensten. Anim. Genet. Universität St. Gallen.

Hudson, J., 2006. Institutional trust and subjective well-being across the EU. Kyklos 59, 43-62.

Hulland, J., 1999. Use of Partial Least Squares (PLS) in Strategic Management Research: A Review of Four Recent Studies. Strateg. Manag. J. 20, 195-204.

International Transport Forum, 2015. Urban Mobility System Upgrade: How shared self-driving cars could change city traffic. https://doi.org/10.1007/s10273-016-2048-3

Kahn, M.E., 2007. Do greens drive Hummers or hybrids? Environmental ideology as a determinant of consumer choice. J. Environ. Econ. Manage. 54, 129-145.

Kim, Y.J., Chun, J.U., Song, J., 2009. Investigating the role of attitude in technology acceptance from an attitude strength perspective. Int. J. Inf. Manage. 29, 67-77. https://doi.org/10.1016/j.ijinfomgt.2008.01.011

King, W.R., He, J., 2006. A meta-analysis of the technology acceptance model. Inf. Manag. 43, 740755. https://doi.org/10.1016/j.im.2006.05.003

Koivumäki, T., Pekkarinen, S., Lappi, M., Vaïsänen, J., Juntunen, J., Pikkarainen, M., 2017. Consumer adoption of future mydata-based preventive ehealth services: An acceptance model and survey study. J. Med. Internet Res. 19, 1-15. https://doi.org/10.2196/jmir.7821

Koscher, K., Czeskis, A., Roesner, F., Patel, S., Kohno, T., Checkoway, S., McCoy, D., Kantor, B., Anderson, D., Snachám, H., Savage, S., 2010. Experimental security analysis of a modern automobile, in: Proceedings - IEEE Symposium on Security and Privacy, pp. 447-462. https://doi.org/10.1109/SP.2010.34

Kuhnimhof, T., Buehler, R., Wirtz, M., Kalinowska, D., 2012. Travel trends among young adults in Germany: Increasing multimodality and declining car use for men. J. Transp. Geogr. 24, 443450. https://doi.org/10.1016/j.jtrangeo.2012.04.018

Kulviwat, S., Brunner II, G.C., Kumar, A., Nasco, S.A., Clark, T., 2007. Toward a Unified Theory of Consumer Acceptance Technology. Psychol. Mark. 24, 1059-1084. https://doi.org/10.1002/mar.20196

Kyriakidis, M., Happee, R., de Winter, J.C.F., 2015. Public opinion on automated driving: Results of an international questionnaire among 5000 respondents. Transp. Res. Part F Traffic Psychol. Behav. 32, 127-140.

Lanzendorf, M., 2003. Mobility biographies. A new perspective for understanding travel behaviour Moving through nets: The physical and social dimensions of travel, in: 10th International 
Conference on Travel Behaviour Research, pp. 10-15.

Le Vine, S., Latinopoulos, C., Polak, J., 2014. What is the relationship between online activity and driving-licence-holding amongst young adults? Transportation 41, 1071-1098.

Lee, Y., Kozar, K.A., Larsen, K.R.T., 2003. The technology acceptance model: Past, present, and future. Commun. Assoc. Inf. Syst. 12, 752-780.

Lewis, A., Simmons, M., 2012. P2P Carsharing Service Design: Informing User Experience Development. Sch. Eng. Blekinge Inst. Technol. Karlskrona, Sweden.

Li, H., Raeside, R., Chen, T., McQuaid, R.W., 2012. Population ageing, gender and the transportation system. Res. Transp. Econ. 34, 39-47. https://doi.org/10.1016/j.retrec.2011.12.007

Lin, H.F., 2011. An empirical investigation of mobile banking adoption: The effect of innovation attributes and knowledge-based trust. Int. J. Inf. Manage. 31, 252-260. https://doi.org/10.1016/j.ijinfomgt.2010.07.006

Litman, T., 2015. Autonomous Vehicle Implementation Predictions Implications for Transport Planning, in: Transportation Research Board 94th Annual Meeting, pp. 36-42. https://doi.org/10.1613/jair.301

Litman, T.A., 2006. Changing Transportation Trends and Their Implications for Transport Planning, in: Transportation Research Board 85th Annual Meeting, pp. 27-33.

Lo, C., 2012. Driverless train technology and the London Underground: the great debate [WWW Document]. URL https://www.railway-technology.com/features/featuredriverless-traintechnology/ (accessed 1.28.19).

Lohmöller, J.-B., 2013. Latent variable path modeling with partial least squares. Springer Science \& Business Media, Heidelberg. https://doi.org/10.1007/978-3-642-52512-4

Mahoney, W.P., O'Sullivan, J.M., 2013. Realizing the potential of vehicle-based observations. Bull. Am. Meteorol. Soc. 94, 1007-1018. https://doi.org/10.1175/BAMS-D-12-00044.1

Maia, M.L., Lucas, K., Marinho, G., Santos, E., de Lima, J.H., 2016. Access to the Brazilian CityFrom the perspectives of low-income residents in Recife. J. Transp. Geogr. 55, 132-141. https://doi.org/10.1016/j.jtrangeo.2016.01.001

Martignoni, R., Stanoevska-Slabeva, K., Mueller, D., Hoegg, R., 2008. Evaluation of Future Mobile Services Based on the Technology Acceptance Model., in: European Conference on Information Systems, pp. 1190-1203.

Mayer, K.U., Tuma, N.B., 1990. Event history analysis in life course research, Life course studies. The University of Wisconsin Press.

Mayer, R.C., Davis, J.H., Schoorman, F.D., 1995. An integrative model of organizational trust. Acad. Manag. Rev. 20, 709-734.

Melia, S., Chatterjee, K., Stokes, G., 2018. Is the urbanisation of young adults reducing their driving? Transp. Res. Part A Policy Pract. 118, 444-456. https://doi.org/10.1016/j.tra.2018.09.021

Milakis, D., Van Arem, B., Van Wee, B., 2017. Policy and society related implications of automated driving: A review of literature and directions for future research. J. Intell. Transp. Syst. 21, 324348.

Millard-Ball, A., Schipper, L., 2011. Are we reaching peak travel? Trends in passenger transport in eight industrialized countries. Transp. Rev. 31, 357-378.

Minx, E., Dietrich, R., 2015. Autonomes Fahren: wo wir heute stehen und was noch zu tun ist. Axel Springer SE, Corporate Solutions.

Misell, J., 2014. Ipsos MORI | Poll | Only 18 per cent of Britons believe driverless cars to be an important development for the car industry to focus on [WWW Document]. URL https://ems.ipsos-mori.com/researchpublications/researcharchive/3427/Only-18-per-cent-ofBritons-believe-driverless-cars-to-be-an-important-development-for-the-car-industry-to-focuson.aspx (accessed 1.13.19). 
Mokhtarian, P.L., Salomon, I., 2001. How derived is the demand for travel? Some conceptual and measurement considerations. Transp. Res. Part A Policy Pract. 35, 695-719.

Moore, Gary C., and Izak Benbasat. 1991. "Development of an Instrument to Measure the Perceptions of Adopting an Information Technology Innovation." Information Systems Research 2(3): 192222.

Moos, M., 2016. From gentrification to youthification? The increasing importance of young age in delineating high-density living. Urban Stud. 53, 2903-2920.

Müggenburg, H., Busch-Geertsema, A., Lanzendorf, M., 2015. Mobility biographies: A review of achievements and challenges of the mobility biographies approach and a framework for further research. J. Transp. Geogr. 46, 151-163.

Münzel, K., Boon, W., Frenken, K., Vaskelainen, T., 2018. Carsharing business models in Germany: characteristics, success and future prospects. Inf. Syst. E-bus. Manag. 16, 271-291.

Muromachi, Y., 2017. Experiences of past school travel modes by university students and their intention of future car purchase. Transp. Res. Part A Policy Pract. 104, 209-220.

Nasri, W., Charfeddine, L., 2012. Factors affecting the adoption of Internet banking in Tunisia: An integration theory of acceptance model and theory of planned behavior. J. High Technol. Manag. Res. 23, 1-14. https://doi.org/10.1016/j.hitech.2012.03.001

Newman, P., Kenworthy, J.R., 2011. 'Peak Car Use': Understanding the Demise of Automobile Dependence. World Transp. Policy Pract. 17, 31-42. https://doi.org/http://worldtransportjournal.com/wp-content/uploads/2015/02/wtpp17.2.pdf

Nielsen, T.A.S., 2015. Changes in transport behavior during the financial crisis. An analysis of urban form, location and transport behavior in the greater Copenhagen area 2006-2011. Res. Transp. Econ. 51, 10-19. https://doi.org/10.1016/j.retrec.2015.07.003

Nijland, H., van Meerkerk, J., Hoen, A., 2015. Impact of car sharing on mobility and co2 emissions. PBL Note 1-12.

Norbutas, L., Corten, R., 2018. Sustainability of generalized exchange in the sharing economy: the case of the "freecycling" Facebook groups. Int. J. Commons 12, 111-133.

Nordhoff, S., van Arem, B., Happee, R., 2016. Conceptual Model to Explain, Predict, and Improve User Acceptance of Driverless Podlike Vehicles. Transp. Res. Rec. J. Transp. Res. Board 2602, 60-67. https://doi.org/10.3141/2602-08

Nykvist, B.B., Whitmarsh, L., 2008. A multi-level analysis of sustainable mobility transitions: Niche development in the UK and Sweden. Technol. Forecast. Soc. Change 75, 1373-1387. https://doi.org/10.1016/J.TECHFORE.2008.05.006

Nysveen, H., Pedersen, P.E., Thorbjørnsen, H., 2005. Explaining intention to use mobile chat services: moderating effects of gender. J. Consum. Mark. 22, 247-256. https://doi.org/10.1108/07363760510611671

Oakil, A.T.M., Ettema, D., Arentze, T., Timmermans, H., 2011b. A longitudinal analysis of the dependence of the commute mode switching decision on mobility decisions and life cycle events, in: 16th International Conference of Hong Kong Society for Transportation Studies, pp. 1-8.

Oakil, A.T.M., Ettema, D., Arentze, T., Timmermans, H., 2011a. Longitudinal Model of Longer-Term Mobility Decisions: Framework and First Empirical Tests. J. Urban Plan. Dev. 137, 220-229. https://doi.org/10.1061/(asce)up.1943-5444.0000066

Oxley, J., Whelan, M., 2008. It cannot be all about safety: the benefits of prolonged mobility. Traffic Inj. Prev. 9, 367-378.

Ozaki, R., Dodgson, M., 2010. Adopting and consuming innovations. Prometheus 28, 311-326.

Pakusch, C., Stevens, G., Boden, A., Bossauer, P., 2018a. Unintended Effects of Autonomous Driving: A Study on Mobility Preferences in the Future. Sustainability 10, 1-22. https://doi.org/10.3390/su10072404 
Pakusch, C., Stevens, G., Bossauer, P., Weber, T., 2018b. The Users' Perspective on Autonomous Driving - A Comparative Analysis of Partworth Utilities, in: Proceedings of the 15th International Joint Conference on E-Business and Telecommunications, pp. 139-146. https://doi.org/10.5220/0006843203050312

Papagiannakis, A., Baraklianos, I., Spyridonidou, A., 2018. Urban travel behaviour and household income in times of economic crisis: Challenges and perspectives for sustainable mobility. Transp. Policy 65, 51-60. https://doi.org/10.1016/j.tranpol.2016.12.006

Pavone, M., Smith, S.L., Frazzoli, E., Rus, D., 2012. Robotic load balancing for mobility-on-demand systems. Int. J. Rob. Res. 31, 839-854.

Pedersen, P.E., 2005. Adoption of mobile Internet services: An exploratory study of mobile commerce early adopters. J. Organ. Comput. Electron. Commer. 15, 203-222.

Pedersen, P.E., Nysveen, H., 2003. Usefulness and self-expressiveness: extending TAM to explain the adoption of a mobile parking service, in: 16th Electronic Commerce Conference, pp. 705-717.

Peters, A., Agosti, R., Popp, M., Ryf, B., 2011. Electric mobility-a survey of different consumer groups in Germany with regard to adoption, in: Proceedings to ECEEE Summer Study. Belambra Presque-ile de Giens France, pp. 1-17.

Peters, A., Doll, C., Kley, F., Möckel, M., Plötz, P., Zanker, A., Wolfgang, S., Axel, S., Thielmann, C., Wietschel, M., 2012. Konzepte der Elektromobilität und deren Bedeutung für Wirtschaft, Gesellschaft und Umwelt. Innov. für das Büro für Tech. beim Dtsch. Bundestag, Arbeitsbericht 308. https://doi.org/10.3390/ijerph13010135

Phelps, J., Nowak, G., Ferrell, E., 2000. Privacy concerns and consumer willingness to provide personal information. J. Public Policy Mark. 19, 27-41.

Podsakoff, P.M., MacKenzie, S.B., Podsakoff, N.P., 2012. Sources of Method Bias in Social Science Research and Recommendations on How to Control It. Annu. Rev. Psychol. 63, 539-569.

Puschmann, T., Alt, R., 2016. Sharing economy. Bus. Inf. Syst. Eng. 58, 93-99. https://doi.org/10.1007/s12599-015-0420-2

Rasouli, S., Timmermans, H., 2017. Models of Behavioral Change and Adaptation, in: Life-Oriented Behavioral Research for Urban Policy. Springer Japan, Tokyo, pp. 451-477. https://doi.org/10.1007/978-4-431-56472-0_16

Redmond, L.S., Mokhtarian, P.L., 2001. The positive utility of the commute: modeling ideal commute time and relative desired commute amount. Transportation 28, 179-205. https://doi.org/10.1023/A:1010366321778

Ringle, C.M., Sarstedt, M., Straub, D.W., 2012. Editor's Comments: A Critical Look at the Use of PLS-SEM. MIS Q. 36, iii-xiv.

Roberts, J.A., 1995. Profiling Levels of Socially Responsible Consumer Behavior: A Cluster Analytic Approach and Its Implications for Marketing. J. Mark. Theory Pract. 3, 97-117. https://doi.org/10.1080/10696679.1995.11501709

Rödel, C., Stadler, S., Meschtscherjakov, A., Tscheligi, M., 2014. Towards autonomous cars: the effect of autonomy levels on acceptance and user experience, in: Proceedings of the 6th International Conference on Automotive User Interfaces and Interactive Vehicular Applications. ACM, pp. 1-8.

Rogers, E.M., 2010. Diffusion of innovations. The Free Press, New York.

Saadé, R., Bahli, B., 2005. The impact of cognitive absorption on perceived usefulness and perceived ease of use in on-line learning: an extension of the technology acceptance model. Inf. Manag. 42, 317-327.

Schaefers, T., 2013. Exploring carsharing usage motives: A hierarchical means-end chain analysis. Transp. Res. Part A Policy Pract. 47, 69-77.

Schalock, R.L., Bonham, G.S., Verdugo, M.A., 2008. The conceptualization and measurement of 
quality of life: Implications for program planning and evaluation in the field of intellectual disabilities. Eval. Program Plann. 31, 181-190.

Scheiner, J., 2018. Why is there change in travel behavior? In search of a theoretical framework for mobility biographies. Erdkunde 72, 41-62.

Scheiner, J., 2014. The gendered complexity of daily life: Effects of life-course events on changes in activity entropy and tour complexity over time. Travel Behav. Soc. 1, 91-105. https://doi.org/10.1016/j.tbs.2014.04.001

Scheiner, J., Holz-Rau, C., 2013. A comprehensive study of life course, cohort, and period effects on changes in travel mode use. Transp. Res. Part A Policy Pract. 47, 167-181.

Schepers, J., Wetzels, M., 2007. A meta-analysis of the technology acceptance model: Investigating subjective norm and moderation effects. Inf. Manag. 44, 90-103.

Schmidt, A., Reers, J., Gerhardy, A., 2018. Mobility as a Service | Mapping a Route Towards Future Success in the New Automotive Ecosystem [WWW Document]. URL https://www.accenture.com/t20180115T110050Z__w_/in-en/_acnmedia/PDF-69/AccentureMobility-As-A-Service.pdf (accessed 1.3.19).

Schoenduwe, R., Mueller, M.G., Peters, A., Lanzendorf, M., 2015. Analysing mobility biographies with the life course calendar: a retrospective survey methodology for longitudinal data collection. J. Transp. Geogr. 42, 98-109.

Schoettle, B., Sivak, M., 2014. A survey of public opinion about connected vehicles in the US, the UK, and Australia, in: 2014 International Conference on Connected Vehicles and Expo (ICCVE). IEEE, pp. 687-692.

Shaheen, S.A., Cohen, A.P., 2013. Carsharing and personal vehicle services: worldwide market developments and emerging trends. Int. J. Sustain. Transp. 7, 5-34.

Shaheen, S.A., Mallery, M.A., Kingsley, K.J., 2012. Research in Transportation Business \& Management Personal vehicle sharing services in North America. RTBM 3, 71-81. https://doi.org/10.1016/j.rtbm.2012.04.005

Shanker, R., Jonas, A., Devitt, S., Huberty, K., Flannery, S., Greene, W., Swinburne, B., Locraft, G., Wood, A., Weiss, K., 2013. Autonomous cars: Self-driving the new auto industry paradigm, in: Morgan Stanley Blue Paper. Morgan Stanley \& Co. LLC, pp. 1-109.

Sharmeen, F., Arentze, T., Timmermans, H., 2014. An analysis of the dynamics of activity and travel needs in response to social network evolution and life-cycle events: a structural equation model. Transp. Res. Part A Policy Pract. 59, 159-171.

Sheldon, K.M., Ryan, R., Reis, H.T., 1996. What makes for a good day? Competence and autonomy in the day and in the person. Personal. Soc. Psychol. Bull. 22, 1270-1279.

Smith, O., 2017. Commute well-being differences by mode: Evidence from Portland, Oregon, USA. J. Transp. Heal. 4, 246-254.

Stark, J., Bartana, I.B., Fritz, A., 2015. Examining mobility behaviour among youth-a progress report. Transp. Res. Procedia 11, 481-491.

Sun, H., Zhang, P., 2006. Causal relationships between perceived enjoyment and perceived ease of use: An alternative approach. J. Assoc. Inf. Syst. 7, 618-645.

SWEG, 2018. Große Resonanz und funktionierende Technik [WWW Document]. URL https://www.sweg.de/html/aktuell/aktuell_u.html?\&m=420\&artikel=11263\&cataktuell=660

Thorpe, J., Motwani, E., 2017. Nudging people into autonomous vehicles [WWW Document]. URL https://www.pwc.com.au/publications/pdf/nudging-people-into-autonomous-vehicles.pdf (accessed 5.12.18)

Trommer, S., Kolarova, V., Fraedrich, E., Kröger, L., Kickhöfer, B., Kuhnimhof, T., Lenz, B., Phleps, P., 2016. Autonomous driving-the impact of vehicle automation on mobility behaviour. Ifmo 171. 
Tussyadiah, I.P., 2015. An exploratory study on drivers and deterrents of collaborative consumption in travel, in: Information and Communication Technologies in Tourism 2015. Springer, pp. 817830.

Ulfarsson, G.F., Steinbrenner, A., Valsson, T., Kim, S., 2015. Urban household travel behavior in a time of economic crisis: Changes in trip making and transit importance. J. Transp. Geogr. 49, 68-75.

UN-DESA, 2014. 2014 Revision of the World Urbanization Prospects, World Urbanization Prospects.

van der Waerden, P., Timmermans, H., Borgers, A., 2003. The Influence of Key Events and Critical Incidents on Transport Mode Choice Switching Behaviour: A Descriptive Analysis, in: 10th International Conference on Travel Behaviour Research, pp. 1-23.

Venkatesh, V., 2000. Determinants of perceived ease of use: Integrating control, intrinsic motivation, and emotion into the technology acceptance model. Inf. Syst. Res. 11, 342-365. https://doi.org/10.1287/isre.11.4.342.11872

Venkatesh, V., Bala, H., 2008. Technology acceptance model 3 and a research agenda on interventions. Decis. Sci. 39, 273-315.

Venkatesh, V., Morris, M.G., Davis, G.B., Davis, F.D., 2003. User acceptance of information technology: Toward a unified view. MIS Q. 27, 425-478.

Venkatesh, V., Thong, J.Y.L., Xu, X., 2012. Consumer acceptance and use of information technology: extending the unified theory of acceptance and use of technology. MIS Q. 36, 157-178.

Verberne, F.M.F., Ham, J., Midden, C.J.H., 2012. Trust in smart systems: Sharing driving goals and giving information to increase trustworthiness and acceptability of smart systems in cars. Hum. Factors 54, 799-810.

Verhoeven, M., Arentze, T., Timmermans, H., van der Waerden, P., 2007. Simulating the influence of life trajectory events on transport mode behavior in an agent-based system, in: 2007 IEEE Intelligent Transportation Systems Conference. IEEE, pp. 107-112.

Verhoeven, M., Arentze, T., Timmermans, H., van der Waerden, P., 2005a. Examining temporal effects of lifecycle events on transport mode choice decisions. Int. J. Urban Sci. 11, 1-13. https://doi.org/10.1080/12265934.2007.9693603

Verhoeven, M., Arentze, T., Timmermans, H.J.P., Van der Waerden, P., 2005b. Modeling the impact of key events on long-term transport mode choice decisions: decision network approach using event history data. Transp. Res. Rec. 1926, 106-114.

Verhoeven, M., Arentze, T.A., Timmermans, H.J.P., van der Waerden, P., 2006. Modeling the influence of structural lifecycle events on activity-travel decisions using a structure learning algorithm, in: 11th International Conference on Travel Behaviour Research. Kyoto, Japan, pp. 122.

Vijayasarathy, L.R., 2004. Predicting consumer intentions to use on-line shopping: the case for an augmented technology acceptance model. Inf. Manag. 41, 747-762.

Wang, B., Rasouli, S., Timmermans, H., Shao, C., 2018. Relationships between consecutive long-term and mid-term mobility decisions over the life course: a Bayesian network approach. Transp. Res. Rec. 2672, 159-170.

Wang, G., Dou, W., Zhou, N., 2008. Consumption attitudes and adoption of new consumer products: a contingency approach. Eur. J. Mark. 42, 238-254.

Wheatley, D., 2014. Travel-to-work and subjective well-being: A study of UK dual career households. J. Transp. Geogr. 39, 187-196.

Witzke, S., 2016. Mobilität, Verkehr und Nachhaltigkeit, in: Carsharing Und Die Gesellschaft von Morgen. Springer Fachmedien Wiesbaden, pp. 5-6. https://doi.org/10.1007/978-3-658-118419_2

Worldometers, 2019. Germany Population (2019) - Worldometers [WWW Document]. URL 
http://www.worldometers.info/world-population/germany-population/ (accessed 1.24.19).

Wu, J.-H., Wang, S.-C., 2005. What drives mobile commerce?: An empirical evaluation of the revised technology acceptance model. Inf. Manag. 42, 719-729.

$\mathrm{Wu}$, J., Lederer, A., 2009. A meta-analysis of the role of environment-based voluntariness in information technology acceptance. MIS Q. 33, 419-432.

Wu, K., Zhao, Y., Zhu, Q., Tan, X., Zheng, H., 2011. A meta-analysis of the impact of trust on technology acceptance model: Investigation of moderating influence of subject and context type. Int. J. Inf. Manage. 31, 572-581.

Xiong, Y., Zhang, J., 2017. Empirical Evidence of Behavioral Interdependencies Across Life Choices, in: Life-Oriented Behavioral Research for Urban Policy. Springer Japan, Tokyo, pp. 9-77. https://doi.org/10.1007/978-4-431-56472-0_2

Xiong, Y., Zhang, J., 2014. Applying a life-oriented approach to evaluate the relationship between residential and travel behavior and quality of life based on an exhaustive CHAID approach. Procedia-Social Behav. Sci. 138, 649-659.

Yamagishi, T., Cook, K.S., 1993. Generalized exchange and social dilemmas. Soc. Psychol. Q. 56, 235-248.

Ye, S., Ho, K.K.W., 2019. Would you feel happier if you have more protection behaviour? A panel survey of university students in Japan. Behav. Inf. Technol. 38, 422-434.

Zeithaml, V.A., 1988. Consumer perceptions of price, quality, and value: a means-end model and synthesis of evidence. J. Mark. 52, 2-22.

Zhang, J., 2017a. Life-Oriented Approach, in: Life-Oriented Behavioral Research for Urban Policy. Springer Japan, Tokyo, pp. 1-8. https://doi.org/10.1007/978-4-431-56472-0_1

Zhang, J., 2017b. Life-Oriented Behavioral Research for Urban Policy. Springer Japan, Tokyo. https://doi.org/10.1007/978-4-431-56472-0

Zhang, J., 2014. Revisiting residential self-selection issues: A life-oriented approach. J. Transp. Land Use 7, 29-45.

Zhang, J., 2009. Subjective well-being and activity-travel behavior analysis: applying day reconstruction method to explore affective experience during travel, in: Proceedings of the 14th International Conference of Hong Kong Society for Transportation Studies. Hong Kong, pp. 439-449.

Zhang, J., Van Acker, V., 2017. Life-oriented travel behavior research: An overview. Transp. Res. Part A 104, 167-178. https://doi.org/10.1016/j.tra.2017.06.004

Zhang, J., Xiong, Y., 2015. Effects of multifaceted consumption on happiness in life: a case study in Japan based on an integrated approach. Int. Rev. Econ. 62, 143-162.

Zumkeller, D., Chlond, B., Manz, W., 2004. Infrastructure development in Germany under stagnating demand conditions: a new paradigm? Transp. Res. Rec. 1864, 121-128. 


\section{Appendix}

Table A1. Operationalization of Theoretical Constructs

\begin{tabular}{|c|c|c|}
\hline Construct & Items & References \\
\hline \multirow{5}{*}{$\begin{array}{l}\text { Intention } \\
\text { to Use }\end{array}$} & I intend to use SDPBs in the future. & (Davis, 1989) \\
\hline & $\begin{array}{l}\text { As I have already used a SDPB, I think I will use one again if } \\
\text { possible. }\end{array}$ & \\
\hline & If I had the opportunity, I would intend to use SDPBs regularly. & \\
\hline & If I had the opportunity, I would try to use SDPBs regularly. & \\
\hline & When I have the opportunity, I plan to use SDPBs regularly. & \\
\hline \multirow{4}{*}{$\begin{array}{l}\text { Attitude } \\
\text { Toward } \\
\text { Use }\end{array}$} & I find the use of SDPBs unpleasant/pleasant. & (Davis, 1989) \\
\hline & I find the use of SDPBs uninteresting/interesting. & \\
\hline & I find the use of SDPBs to be disadvantageous/advantageous. & \\
\hline & I find the use of the autonomous bus meaningless/meaningful. & \\
\hline
\end{tabular}

Perceived The SDPB allows me to move faster.

(Davis, 1989)

Usefulness The use of the SDPB increases my productivity when moving around.

The use of the SDPB enables me to move more effectively.

The SDPB is a useful means of transport.

Perceived The use of the SDPB is clear and understandable.

(Davis, 1989)

Ease of The use of the SDPB does not require mental effort.

Use

The SDPB is easy to use.

The SDPB is simple to use.

Ecological In the past, I bought products because they cause fewer emis-

Awareness sions or pollutants.

(Roberts, 1995)

When I have a choice between two identical products, I choose the more environmentally friendly one.

If I am aware of the negative environmental effects of some products, I try not to buy them.

When I have a choice, I always prefer products that have the least negative impact on the environment.

Openness If I had to share transportation options with other people, I could

to Shared never be sure they were available when I needed them.*

(Hirschl et al.,

Use

I think it is time-consuming to coordinate the sharing of transport with other users.*

For me it is important to have a vehicle available whenever I want to use it.* 
Perceived I find the use of the SDPB pleasant.

(Davis et al., 1992)

Enjoyment The use of the SDPB gives me pleasure.

I enjoy the use of the SDPB.

Trust I find the SDPB to be reliable.

(Choi and Ji, 2015)

I find the SDPB to be trustworthy.

All in all, I trust the SDPB.

I think the SDPB is safe.

Privacy I feel uncomfortable that my use of SDPBs can be easily moni-

Concerns tored.

(Phelps et al.,

I have the feeling that my privacy can be compromised because

SDPB use can be tracked.

I can imagine that the operator could violate my privacy by monitoring the SDPB.

I believe that the use of SDPBs makes it easier for my privacy to be invaded.

Relative Compared to my other means of transportation, the SDPB ena-

Advantage bles me to reach my destination faster.

Moore and Benba-

Compared to my other means of transportation, the SDPB improves the quality of my transportation. sat (1991)

Compared to my other means of transportation, the SDPB makes it easier for me to get around.

The SDPB offers a better performance than my other means of transport.

Compared to my other means of transportation, the SDPB is more effective for reaching my destination.

\begin{tabular}{ll}
\hline $\begin{array}{l}\text { Price } \\
\text { Evaluation }\end{array}$ & $\begin{array}{l}\text { The advantages of using a SDPB outweigh the additional costs } \\
\text { of using it. }\end{array}$ \\
& For the use of a SDPB, I would be willing to pay more than \\
& what I would pay for the same route by other means of transport. \\
& For me, the price is the decisive criterion for the use of the \\
& SDPB.
\end{tabular}

Social People who influence my behavior tend to think that I should

Network use the SDPB.

(Ajzen, 1991)

People who are important to me are of the opinion that I should use the SDPB.

My social environment would tend to expect me to use the SDPB.

People whose opinion I appreciate think that I should use the SDPB.

*negative polarity 
Table A2. Cross-Loadings

\begin{tabular}{|c|c|c|c|c|c|c|c|c|c|c|c|c|c|c|c|}
\hline & ATT & EA & EDU & FB & INT & OSU & PC & PE & PENJ & PEOU & PU & $\mathbf{R A}$ & RES & SN & TR \\
\hline ATT02 & .79 & .08 & .06 & -.04 & .53 & -.11 & -.13 & .20 & .54 & .39 & .34 & .31 & .09 & .29 & .4 \\
\hline ATT03 & .82 & .22 & .01 & -.02 & .50 & -.18 & -.13 & .23 & .63 & .49 & .36 & .28 & .01 & .31 & $.4 C$ \\
\hline ATT05 & .87 & .27 & .02 & .03 & .55 & -.17 & -.13 & .26 & .49 & .37 & .50 & .40 & .08 & .49 & 4 \\
\hline ATT06 & .84 & .26 & .08 & -.02 & .59 & -.13 & -.17 & .25 & .50 & .44 & .53 & .40 & .04 & .45 & .5 \\
\hline EDU01 & .05 & .05 & 1 & .35 & .05 & .01 & -.05 & -.07 & .06 & .08 & -.02 & -.05 & .35 & -.10 & .10 \\
\hline FB01 & -.01 & .04 & .35 & 1 & .08 & .03 & -.01 & .02 & 0 & .06 & -.01 & -.02 & .27 & .04 & .02 \\
\hline INT01 & .58 & .22 & .06 & .09 & .85 & -.20 & -.18 & .24 & .46 & .4 & .42 & .30 & .09 & .43 & .48 \\
\hline INT02 & .56 & .30 & .06 & .07 & .88 & -.22 & -.19 & .27 & .48 & .44 & .38 & .29 & .15 & .39 & .4 \\
\hline INT03 & .62 & .25 & .05 & .1 & .94 & -.15 & -.18 & .28 & .54 & .46 & .43 & .33 & .15 & .45 & .51 \\
\hline INT04 & .62 & .25 & .02 & .05 & .95 & -.15 & -.16 & .31 & .54 & .47 & .44 & .36 & .11 & .43 & .51 \\
\hline INT05 & .60 & .29 & .04 & .05 & .92 & -.15 & -.19 & .29 & .50 & .43 & .40 & .31 & .06 & .42 & .47 \\
\hline EA02 & .19 & .85 & .08 & .04 & .24 & -.10 & -.11 & .20 & .25 & .23 & .23 & .12 & -.01 & .18 & .18 \\
\hline EA03 & .23 & .88 & 0 & .03 & .22 & -.10 & -.09 & .25 & .24 & .16 & .22 & .25 & -.01 & .24 & .18 \\
\hline EA04 & .26 & .93 & .05 & .03 & .29 & -.14 & -.14 & .28 & .28 & .2 & .25 & .21 & -.03 & .25 & .25 \\
\hline OSU02 & -.16 & -.07 & .09 & .06 & -.12 & .84 & .1 & -.16 & -.10 & -.09 & -.05 & 0 & -.08 & -.14 & -.03 \\
\hline OSU03 & -.13 & -.10 & 0 & -.03 & -.14 & .87 & .14 & -.14 & -.15 & -.12 & -.02 & -.07 & -.12 & -.11 & -.11 \\
\hline OSU04 & -.17 & -.14 & -.04 & .03 & -.21 & .92 & .23 & -.18 & -.16 & -.11 & -.18 & -.09 & -.20 & -.14 & -.07 \\
\hline PE01 & .28 & .25 & -.08 & 0 & .29 & -.19 & 0 & .94 & .26 & .19 & .20 & .24 & 0 & .25 & .26 \\
\hline PE02 & .26 & .26 & -.05 & .04 & .29 & -.16 & -.04 & .94 & .29 & .19 & .24 & .27 & -.02 & .23 & .15 \\
\hline RA01 & .39 & .22 & -.03 & -.05 & .29 & -.05 & -.09 & .24 & .35 & .16 & .54 & .88 & .03 & .38 & 2 \\
\hline RA02 & .43 & .18 & 0 & -.02 & .38 & -.04 & -.06 & .23 & .39 & .20 & .50 & .89 & .02 & .36 & .30 \\
\hline RA03 & .35 & .14 & -.05 & -.01 & .32 & -.05 & -.08 & .21 & .39 & .13 & .49 & .89 & -.04 & .37 & .31 \\
\hline RA04 & .36 & .21 & -.07 & 0 & .29 & -.08 & -.08 & .27 & .37 & .12 & .49 & .91 & -.06 & .37 & .27 \\
\hline RA05 & .35 & .21 & -.10 & 0 & .27 & -.08 & -.06 & .25 & .36 & .15 & .49 & .90 & -.02 & .35 & .32 \\
\hline RES01 & .07 & -.02 & .35 & .27 & .12 & -.16 & -.11 & -.01 & .03 & .11 & .09 & -.01 & 1 & -.07 & .01 \\
\hline SN01 & .43 & .25 & -.11 & .02 & .43 & -.13 & -.12 & .24 & .33 & .23 & .42 & .36 & -.07 & .95 & .34 \\
\hline SN02 & .45 & .25 & -.10 & .01 & .44 & -.15 & -.15 & .25 & .35 & .20 & .47 & .43 & -.06 & .94 & .32 \\
\hline SN03 & .42 & .20 & -.09 & .07 & .42 & -.13 & -.12 & .21 & .31 & .21 & .42 & .38 & -.03 & .93 & .28 \\
\hline SN04 & .48 & .24 & -.07 & .03 & .46 & -.15 & -.15 & .25 & .40 & .27 & .43 & .38 & -.09 & .95 & .35 \\
\hline PC01 & -.16 & -.09 & -.06 & -.06 & -.16 & .17 & .89 & .01 & -.21 & -.08 & -.16 & -.09 & -.10 & -.16 & -.19 \\
\hline PC02 & -.15 & -.11 & -.03 & -.03 & -.20 & .15 & .94 & 0 & -.19 & -.05 & -.15 & -.08 & -.14 & -.13 & -.18 \\
\hline PC03 & -.14 & -.12 & -.04 & .04 & -.19 & .16 & .91 & -.06 & -.21 & -.08 & -.12 & -.07 & -.11 & -.11 & -.16 \\
\hline PC04 & -.17 & -.16 & -.04 & .01 & -.18 & .21 & .90 & -.04 & -.23 & -.11 & -.13 & -.06 & -.06 & -.12 & -.17 \\
\hline TR01 & .56 & .25 & .07 & -.04 & .49 & -.06 & -.18 & .18 & .58 & .43 & .42 & .35 & .01 & .34 & .93 \\
\hline TR02 & .59 & .24 & .11 & 0 & .53 & -.11 & -.22 & .22 & .59 & .49 & .41 & .34 & .04 & .35 & .97 \\
\hline TR03 & .56 & .20 & .08 & .05 & .53 & -.08 & -.18 & .24 & .57 & .48 & .38 & .30 & .01 & .32 & .96 \\
\hline TR04 & .53 & .18 & .10 & .07 & .46 & -.06 & -.16 & .25 & .57 & .48 & .33 & .26 & -.01 & .28 & .94 \\
\hline PEOU01 & .46 & .18 & .08 & .04 & .43 & -.11 & -.05 & .23 & .44 & .88 & .33 & .19 & .04 & .25 & .46 \\
\hline PEOU02 & .47 & .19 & .08 & .04 & .44 & -.07 & -.08 & .15 & .47 & .87 & .33 & .18 & .15 & .24 & .42 \\
\hline PEOU03 & .46 & .21 & .07 & .06 & .45 & -.15 & -.09 & .18 & .47 & .95 & .28 & .13 & .11 & .19 & .46 \\
\hline PEOU04 & .46 & .23 & .07 & .06 & .45 & -.11 & -.10 & .17 & .49 & .95 & .29 & .13 & .09 & .20 & .48 \\
\hline PU01 & .41 & .27 & -.06 & 0 & .34 & -.06 & -.07 & .22 & .29 & .21 & .85 & .52 & .02 & .40 & .30 \\
\hline PU02 & .46 & .21 & -.04 & -.04 & .39 & -.10 & -.11 & .21 & .30 & .25 & .92 & .53 & .07 & .38 & .34 \\
\hline
\end{tabular}




\begin{tabular}{|c|c|c|c|c|c|c|c|c|c|c|c|c|c|c|c|}
\hline PU03 & .43 & .27 & -.02 & -.01 & .39 & -.13 & -.18 & .19 & .31 & .29 & .94 & .53 & .08 & .42 & .37 \\
\hline PU04 & .53 & .17 & .06 & .03 & .47 & -.10 & -.17 & .22 & .35 & .42 & .78 & .39 & .12 & .41 & .40 \\
\hline PENJ01 & .65 & .26 & .10 & -.01 & .50 & -.13 & -.24 & .24 & .89 & .54 & .29 & .39 & .04 & .34 & .60 \\
\hline PENJ02 & .58 & .26 & .04 & .01 & .53 & -.15 & -.20 & .29 & .95 & .46 & .35 & .38 & .04 & .36 & .56 \\
\hline PENJ03 & .56 & .28 & .02 & -.01 & .50 & -.16 & -.19 & .29 & .93 & .42 & .36 & .38 & .01 & .33 & .52 \\
\hline
\end{tabular}

Note. Bolded cells; item loadings; other cells: cross loadings. The items ATT01 and EA01 were dropped due to low factor loadings $(<.7)$; EA: Ecological Attitude; OSU: Openness to Shared Use; PENJ: Perceived Enjoyment; TR: Trust; PC: Privacy Concerns; RA: Relative

Advantage; PE: Price Evaluation; SN: Social Network; RES: Residence; FB: Family Budget; EDU: Education; PU: Perceived Usefulness; PEOU: Perceived Ease of Use; ATT: Attitude; INT: Intention to Use. 